\title{
Study on the Meso-Energy Damage Evolution Mechanism of Single-Joint Sandstone under Uniaxial and Biaxial Compression
}

\author{
Gui-Lin Wang $\mathbb{D}^{1,2,3}$ Tian-Ci Cao $\mathbb{D}^{1},{ }^{1}$ Fan Sun $\mathbb{D}^{1,2}$ Xing-Xiang Wen ${ }^{1}{ }^{1}$, \\ and Liang Zhang $\mathbb{D}^{1}$ \\ ${ }^{1}$ School of Civil Engineering, Chongqing University, Chongqing 400045, China \\ ${ }^{2}$ National Joint Engineering Research Center of Geohazards Prevention in the Reservoir Areas, Chongqing 400045, China \\ ${ }^{3}$ Key Laboratory of New Technology for Construction of Cities in Mountain Area: Chongqing University, \\ Chongqing 400045, China
}

Correspondence should be addressed to Fan Sun; 1319469487@qq.com

Received 26 June 2021; Revised 14 September 2021; Accepted 15 September 2021; Published 6 October 2021

Academic Editor: José António Fonseca de Oliveira Correia

Copyright ( 2021 Gui-Lin Wang et al. This is an open access article distributed under the Creative Commons Attribution License, which permits unrestricted use, distribution, and reproduction in any medium, provided the original work is properly cited.

Energy conversion and release occur through the entire deformation and failure process in jointed rock masses, and the accumulation and dissipation of rock mass energy in engineering can reveal the entire process of deformation and instability. This study uses PFC2D to carry out numerical simulation tests on single-joint sandstone under uniaxial compression and biaxial compression, respectively, and analyse the influence of joint inclination, length, and confining pressure on the meso-energy conversion process and phase evolution of jointed sandstone. Through analysis, it is found that the input meso total strain energy is transformed into meso dissipated energy and meso-elastic strain energy. Macroscopic and microscopic joint sandstone law is consistent with the overall energy evolution; and the difference is reflected in two aspects: (1) the microlevel energy evolution has no initial compaction energy consumption section and (2) the linear energy storage section before the macroenergy evolution peak can be subdivided into two sections in the meso-level energy evolution. Under uniaxial compression, the energy values at the characteristic points of the meso-level energy evolution phases first asymmetrically decrease and then increase with the increase of the joint inclination. The initiation point of jointed sandstone is significantly affected by the length of the joint, and the degradation effect of the meso-energy at the damage point and peak point weakens with the increase of the joint length. Comparing the data obtained from the PFC numerical simulation with the experimental data, it is found that the error is small, which shows the feasibility of the numerical model in this paper. Under biaxial compression, the accumulation rate of meso-elastic strain at the peak point of the jointed sandstone first decreases and then increases with the joint inclination angle. After the peak of jointed sandstone, the rate of sudden change of meso-energy change decreases with the increase of joint length. The conditions of high confining pressure will promote the meso-accumulated damage degree of the jointed sandstone before the peak, while inhibiting the meso-energy and the mutation degree of the damage after the peak. The higher the confining pressure, the more obvious the joint length and inclination effect characteristics of the elastic strain energy at the peak point of the jointed sandstone.

\section{Introduction}

The failure of rock is a process of energy conversion and transfer involving the continuous exchange of matter and energy with the outside world, and its final failure is a state instability phenomenon driven by internal energy [1-3]. Many scholars have analysed the damage and destruction processes of rocks from an energy perspective [4-6]. Chen et al. $[7,8]$ studied the fracture evolution and energy damage evolution mechanism of deeply buried carbonaceous slate.
Wang et al. [9] studied the energy mechanism of the strength weakening of discontinuous jointed sandstone under uniaxial compression with a dip of $45^{\circ}$ through uniaxial compression tests. The crack propagation and failure criteria for a jointed rock mass were then constructed based on the rate of change of the elastic energy consumption ratio. Zhang and Gao [10] established a self-inhibited evolution model of the energy conversion of loaded rock with axial stress and analysed the energy evolution law of dry and wet red sandstone. Peng et al. [11] established a damage 
evolution model based on conventional triaxial compression tests. Li et al. [12] proposed an energy dissipation damage constitutive model for a jointed rock mass based on the energy principle. Peng et al. [13-15] investigated the energy dissipation and fragment distribution of rock specimens containing symmetrical and asymmetrical cross-fissures under static and dynamic loadings and investigated the energy characteristics of fissured specimens under coupled static and dynamic loads with different loading parameters. Liu et al. [16] revealed the influence of fatigue energy and damage evolution parameters on the mechanical properties of the jointed rock model.

It is difficult for laboratory tests to reveal the relationship between the internal crack development process and the energy change in a rock mass in real-time. The macroenergy of the jointed rock mass is calculated as an integral of the mechanical test data, and thus the accuracy of the results is greatly restricted by the test conditions. The process of using high-pressure water jet cutting to create jointed specimens is generally difficult and expensive due to the influence of the uniformity of the rock itself. Therefore, the establishment of a multiscale mechanical model from a meso-scale perspective can provide a deeper understanding of the rock deformation and failure processes [17, 18]. Xie et al. [19] established a joint damage statistical constitutive model based on the damage statistical mechanics theory and the characteristics of deformation stages. Wong and Einstein [20] studied the microscopic development of white patches and their evolution into macroscopic tensile cracks and shear cracks in marble and the microscopic initiation of hair-line tensile cracks and their evolution into macroscopic tensile cracks in gypsum. With the gradual deepening of the rock energy evolution process, it has been found that numerical simulations can provide significant advantages, such as repeatability, real-time results, economic benefits, and operability. Through the damage caused by the contact between particles, the morphological evolution and crack propagation evolution of the specimen can be accurately captured throughout the entire process, and the fracture mechanism of the medium can be deeply revealed. Therefore, the particle flow method has gradually been applied to the study of basic mechanical properties and fracture characteristics of rock materials [21-25]. For example, the dynamic progressive fracturing process of the cracked chevron-notched Brazilian disc (CCNBD) specimen was numerically assessed via discrete-element method [26]. Liu and Wang [27] used the particle flow numerical method to establish a rock sample with a single prefabricated fracture and studied the effects of concentrated tensile stress and shear stress on airfoil and secondary crack propagation during quasi-static loading. Rashid and George [28] proposed an elastic damage yield criterion algorithm based on energy dissipation and embedded it in numerical software to analyse the stability of the surrounding rock. Zhou [29] studied the anisotropic characteristics of rocks using a triaxial experiment based on the strain energy density factor. The numerical simulation of a particle flow has been performed using the discrete-element method, which can construct any rock shape as a particle assembly. Wang et al.
[4] used numerical simulations to study rock bursts in deep tunnels. Huang and Cen [17] used numerical simulations to conduct an in-depth study of the meso-damage characteristics and energy dissipation mechanism of single-joint granite under successive static-dynamic loads. Zhang et al. [18] used the particle flow method to study the relationship between the rock deformation energy, microcrack evolution, and damage from a meso-scale perspective. Potyondy and Cundall [30] proposed a bonding model suitable for rocks in PFC, which greatly improved the accuracy of numerical methods for simulating the macromechanical and mesomechanical properties of rocks and has been widely used.

The current research is mainly focused on the secondary development of a complete rock energy model algorithm or the exploration of the meso-damage and energy evolution law of lower rock masses before the peak under a certain load. However, in-depth investigations of the phase characteristics of the meso-energy evolution mechanism of jointed rock masses and the correlation between the mesoenergy and damage evolution during the entire loading process under different stress states are still lacking. $\mathrm{Nu}-$ merical simulations of particle flow characteristics can overcome the shortcomings of analysing multicrack failure in macromechanical tests and can allow the corresponding relationship between the stress, cracks, and meso-energy evolution of rock samples under loads to be monitored directly. Therefore, this study uses PFC2D to carry out numerical simulations of a single-joint sandstone under uniaxial and biaxial compression. The data are compared with uniaxial test data to analyse the causes of errors. The relationship between the mechanical characteristics of single-joint sandstone, microcrack initiation law, meso-damage, and energy evolution mechanism is studied from a meso-scale perspective, and the effects of the joint dip, joint length, and confining pressure on the meso-energy damage evolution of jointed sandstone are explored.

\section{Test Program and Equipment}

A rock sample was obtained from a fresh and complete sandstone block located on a rocky slope on the bank of the Three Gorges Reservoir. The selected sandstone is hard and grey in texture, and it has a fine-grained sand-like structure and massive structure. Fine grains of 0.25 to $0.125 \mathrm{~mm}$ are dominant, followed by medium grains of 0.25 to $0.5 \mathrm{~mm}$. The sorting is general, and the rounding is medium. The main mineral composition of the sandstone is as follows: quartz $(50.7 \%)$, plagioclase $(19.4 \%)$, hematite $(9.6 \%)$, calcite (7.6\%), potash feldspar (4.4\%), anhydrite $(2.7 \%)$, and clay minerals (5.6\%). According to indoor rock mass tests, the density of the sandstone in its natural state is $2.27 \mathrm{~g} / \mathrm{cm}^{3}$, the water content is $0.85 \%$, the cohesion is $19.1 \mathrm{MPa}$, and the internal friction angle is $25.2^{\circ}$.

The test piece is a standard cylindrical test piece $(D=50 \mathrm{~mm}, H=100 \mathrm{~mm})$. The complete sandstone is processed into joint samples with a water jet, and the prefabricated joint is filled with gypsum. Testing indicated that the peak strength of the gypsum is approximately $6.6 \mathrm{MPa}$, and the elastic modulus is approximately $0.85 \mathrm{GPa}$. 
The width of the prefabricated joints in the sample is $1 \mathrm{~mm}$. When producing samples with different joint dip angles, the joint length, $2 a$, is $1 \mathrm{~cm}$. The centre of the joint coincides with the centre of the cylindrical sandstone sample, and the joint dip angles, $\alpha$, are $0^{\circ}, 15^{\circ}, 30^{\circ}, 45^{\circ}, 60^{\circ}$, $75^{\circ}$, and $90^{\circ}$. The processed jointed sandstone samples with different joint dip angles are shown in Figure 1(a); when samples with different joint lengths are produced, the dip, $\alpha$, is $45^{\circ}$. The joint lengths, $2 a$, in that case are $1,1.5,2,2.5$, and $3 \mathrm{~cm}$. The processed jointed sandstone samples with different joint lengths are shown in Figure 1(b).

The load is applied using a WADJ-600 microcomputercontrolled electro-hydraulic servo rock mass shear rheological testing machine. The uniaxial compression test adopts vertical displacement control loading with a loading rate of $0.1 \mathrm{~mm} / \mathrm{min}$ until failure of the specimen. The digital image correlation (DIC) equipment is an XT-DIC noncontact strain and deformation measurement system. The test equipment is shown in Figure 2.

The brittleness can be usually determined by the relation between compressive strength and tensile strength; therefore, to better reflect the brittleness of the sample, we conducted a tensile strength test. According to the recommended standards of the International Society of Rock Mechanics (ISRM), the sandstone was processed into samples with a diameter $D$ and a thickness $t$ of $50 \mathrm{~mm}$ and $25 \mathrm{~mm}$, respectively. The AG-IS precision electronic universal material testing machine was used to carry out the Brazilian split test on the sandstone sample. The loading method was displacement control. To ensure the static loading condition, the loading rate was set to $1.67 \times 10^{-6} \mathrm{~s}^{-1}$ $(0.1 \mathrm{~mm} / \mathrm{min})$, the test device is shown in the figure. The formula for calculating the tensile strength of the complete rock is

$$
\sigma_{t}=\frac{2 P}{\pi \mathrm{D} t} .
$$

In the formula, $P$ is the failure load, $D$ is the diameter of the sample, $t$ is the thickness of the sample, and $\sigma t$ is the tensile strength of the rock. According to the results of the Brazilian split test (the ultimate load is $9.343 \mathrm{kN}$ ), the tensile strength of the rock sample can be calculated using the formula to be $4.761 \mathrm{MPa}$ (Figure 3).

\section{Establishment of the Particle Flow Numerical Model}

Based on the results of laboratory tests, PFC2D is used to perform numerical simulations of jointed sandstone under uniaxial and biaxial compression to investigate the relationship between the mechanical characteristics of discontinuous jointed sandstone, microcrack initiation, microscopic damage, and the energy evolution mechanism from a meso-scale perspective. This study aims to reveal the meso-mechanical mechanism of discontinuous jointed sandstone under compression.

PFC2D is a virtual particle flow simulation software based on discrete-element theory and the mechanical behavior of materials from a meso-level perspective. The model in PFC2D is composed of basic units, such as walls, disc particles, bonding, and contact. There is no need to define the macroscopic constitutive relationship and material when applying PFC to calculate, but the microscopic and macroscopic mechanical parameter characteristics of the material need to be related to each other. The cementation between rocks can be simulated by the contact constitutive between particles, and Newton's second motion can explain the mechanical relationship between the particles. The macroscopic morphology of the rock is the physical reaction of the movement of the meso-mineral particles and the bonding friction.

Potyondy and Cundall [30] proposed particle bonding models suitable for simulating rock materials, including contact bonding and parallel bonding. As the parallel bonding model has the advantages of resisting stretching, shearing, and moment effects, it can better simulate the cementation between rock and mineral particles, as shown in Figure 4. This model has been confirmed by many scholars to more accurately simulate the meso-damage process of brittle rocks. Therefore, this paper uses the parallel year festival model for PFC numerical simulation.

Based on the medium, stress homogenisation assumption and one-dimensional assumption, a two-dimensional model is used to study the microcracks and meso-energy evolution law of jointed sandstones during the deformation process. The parallel bonding model [30] is used to establish a sandstone sample with dimensions of $50 \mathrm{~mm} \times 100 \mathrm{~mm}$, and the method of assigning weaker meso-cohesion parameters to particles in a certain range is used to simulate weak fillings. The numerical model contains 13,645 particles and 29,350 contacts, with a minimum radius of $0.25 \mathrm{~mm}$ and a maximum radius of $0.375 \mathrm{~mm}$. The specific numerical model types of the jointed sandstone are listed in Table 1.

For the numerical simulation of the uniaxial compression experiment, the lateral left and right walls are deleted, and the same speed in opposite directions is applied to the upper and lower walls to control the axial displacement. The speed of the upper and lower walls is $0.05 \mathrm{~m} / \mathrm{s}$, as shown in Figure 5(a).

For the numerical simulation of the biaxial compression experiment, a certain speed is applied to the surrounding four walls to maintain a constant confining pressure of the lateral wall; at the same time, the same speed in opposite directions is applied to the vertical walls to simulate axial displacement control loading, as shown in Figure 5(b). The biaxial compression tests considered three different confining pressures of $5 \mathrm{MPa}, 10 \mathrm{MPa}$, and $15 \mathrm{MPa}$.

To simulate the deformation process of jointed sandstone filled with gypsum under uniaxial and biaxial compression, the particles are divided into two groups. The macromechanical parameters of intact sandstone and gypsum were measured based on the indoor uniaxial compression test and calibrated, and then a two-dimensional particle flow numerical model of jointed sandstone with gypsum filling was established. The calibration of intact sandstone and gypsum meso-parameters is carried out as follows: first, the meso-parallel bonding modulus and contact modulus between the particles of the numerical 

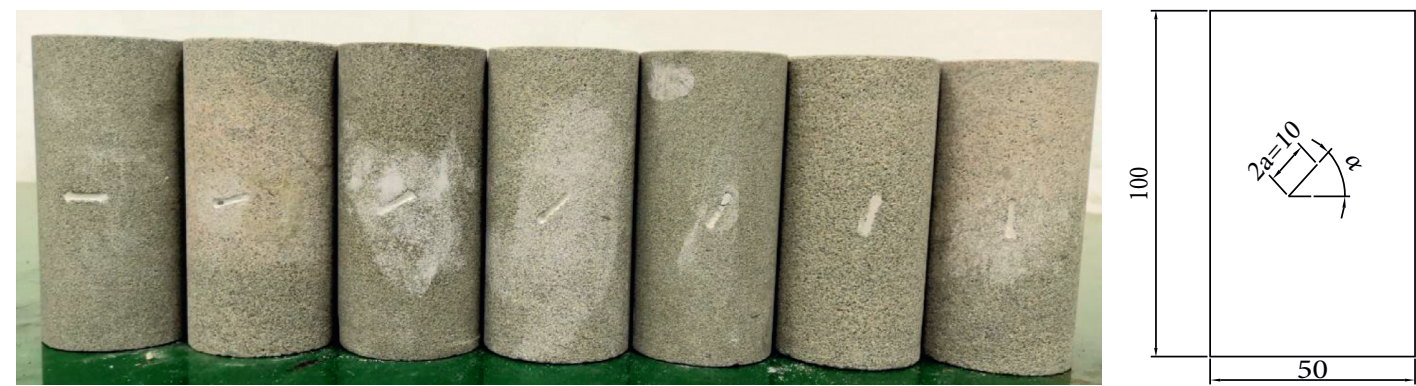

(a)
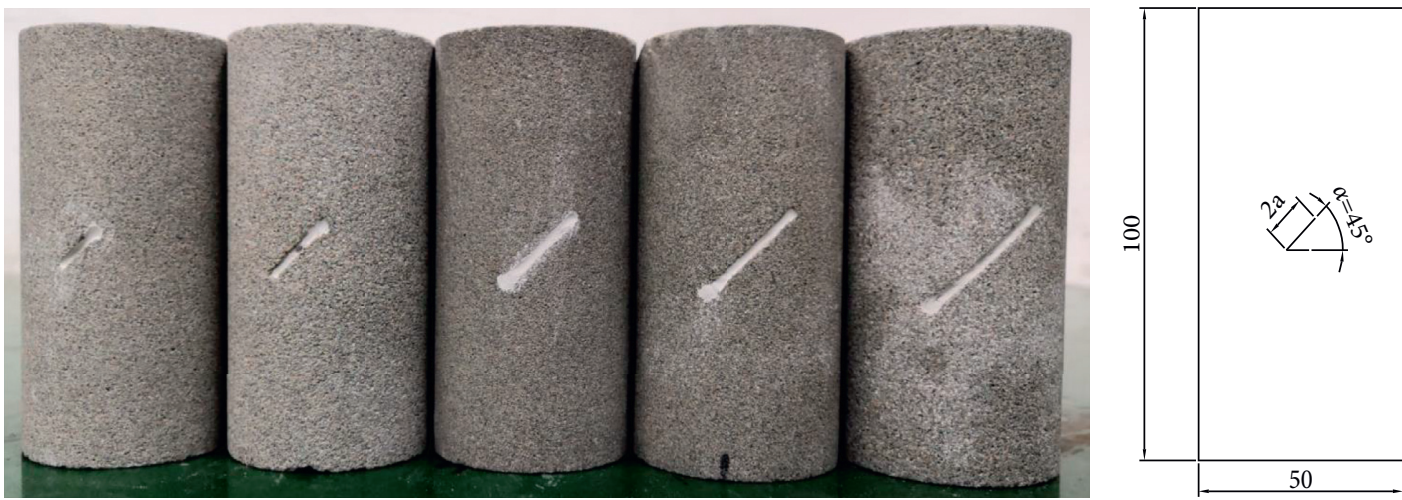

(b)

FIGURE 1: Sandstone specimens and joint position (length unit: $\mathrm{mm}$ ): (a) sandstone specimens with different dip angles of the joint and (b) sandstone specimens with different joint lengths.

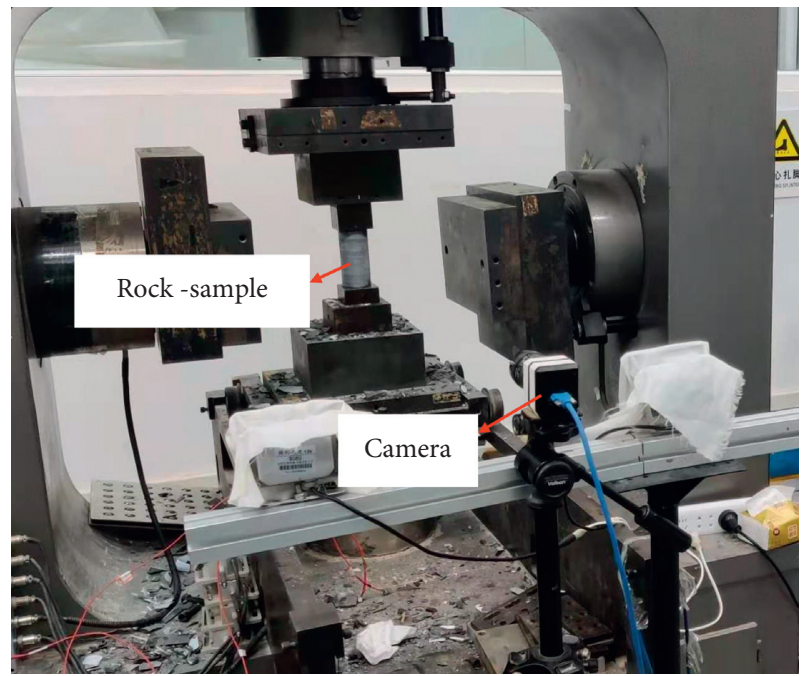

Figure 2: WADJ-600 testing machine and DIC instrument.

model are repeatedly and synchronously adjusted, so that the slope of the stress-strain curve obtained by the numerical simulation is compared with the indoor uniaxial compression, similar or the same as the test result; then adjust the meso-stiffness ratio of the numerical model simultaneously to make Poisson's ratio and failure mode obtained by the numerical model consistent with the test results; then the normal strength and tangential direction of the parallel bonding are adjusted proportionally, so that the peak

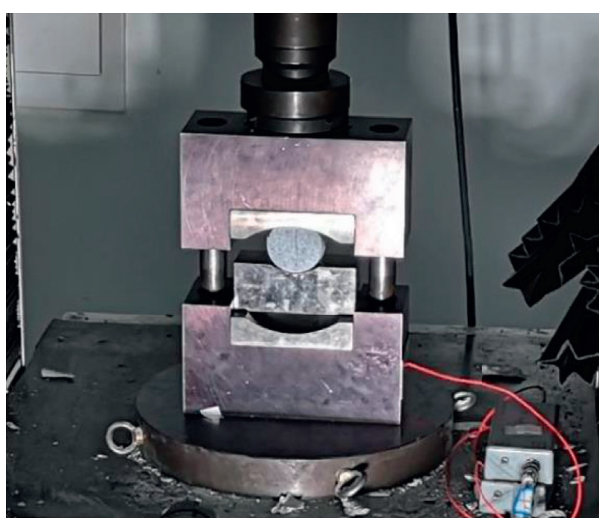

FIGURE 3: AG-IS precision electronic universal material testing machine.

intensity of numerical simulation is similar to that of the experiment test. Finally, through the "trial and error method," the meso-parameters are uniformly calibrated, and finally, a set of meso-parameters similar to the results of the indoor uniaxial compression test are obtained. (The stiffness of the wall is considered infinite), as shown in Table 2. Although the numerical test results are affected by the uniformity of the model particles and cannot reflect the initial compaction stage of the complete sandstone, the particle flow numerical simulation can still show the other stages of sandstone deformation. The macromechanical parameters in the experimental tests and numerical simulations are listed in Table 3. 


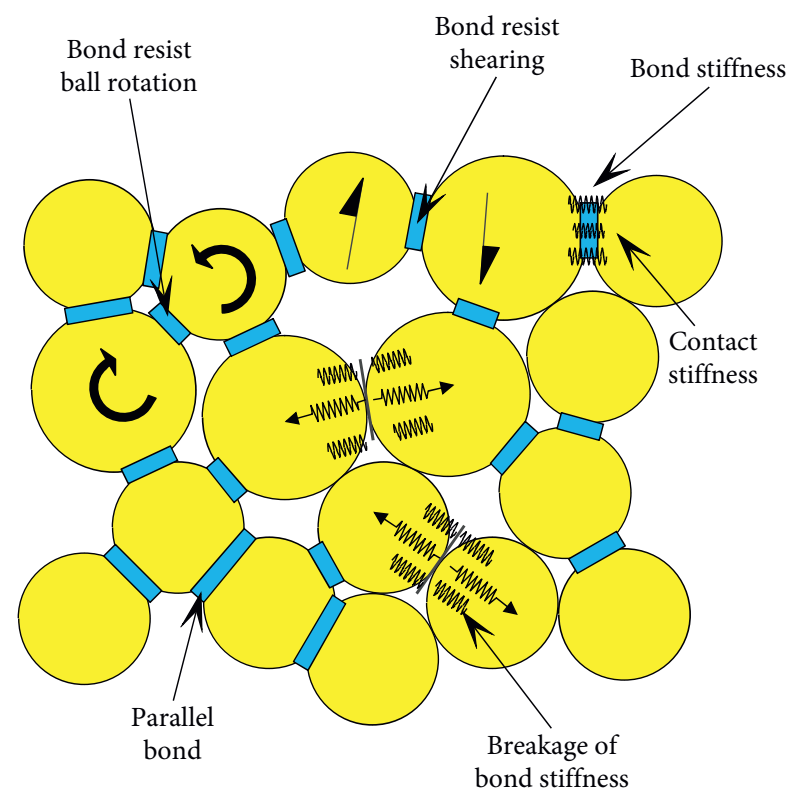

Figure 4: Parallel bond model in discrete-element method [31].

TABLE 1: Joint form of the particle flow numerical model of jointed sandstone.

\begin{tabular}{lccccc}
\hline Joint form & $\begin{array}{c}\text { Model size } \\
(\mathrm{mm} \times \mathrm{mm})\end{array}$ & Joint $\operatorname{dip}\left(^{\circ}\right)$ & Joint length $(\mathrm{cm})$ & Joint width $(\mathrm{cm})$ & Joint location \\
\hline Joint dip & $50 \times 100$ & $0,15,30,45,60,75,90$ & 1 & 0.1 & Joint centre and rock sample centre coincide \\
Joint length & 45 & $1,1.5,2,2.5,3$ & 0.1 \\
\hline
\end{tabular}

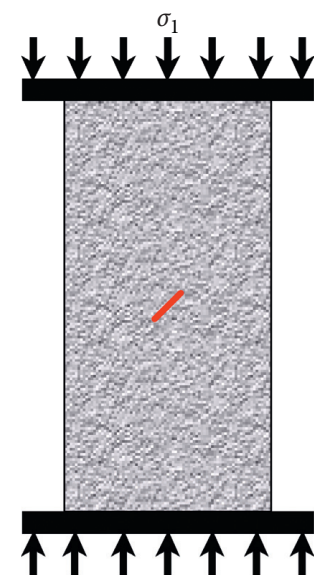

(a)

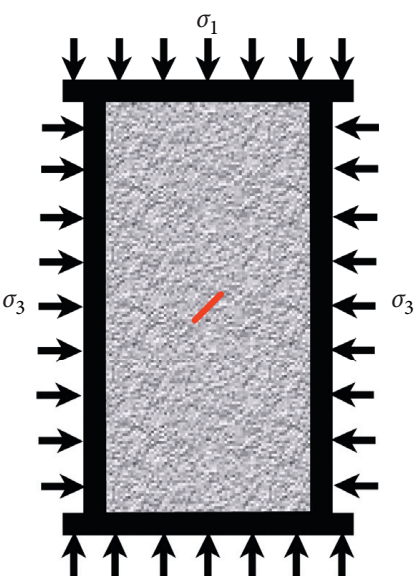

(b)

Figure 5: Loading modes in the particle flow numerical simulations: (a) uniaxial compression simulation and (b) biaxial compression simulation.

\section{Meso-Energy Theory of Jointed Sandstone}

Assuming that there is no heat exchange between the rock mass and the outside under load, then according to the first law of thermodynamics, the work, $G$, performed by the external load on the jointed sandstone is as follows:

$$
G=G_{d}+G_{e}
$$

where $G_{d}$ is the dissipated energy of the jointed sandstone and $G_{e}$ is the elastic strain energy of the jointed sandstone.

According to the energy tracking theory in discrete elements [32], the total energy absorbed by the discrete- 


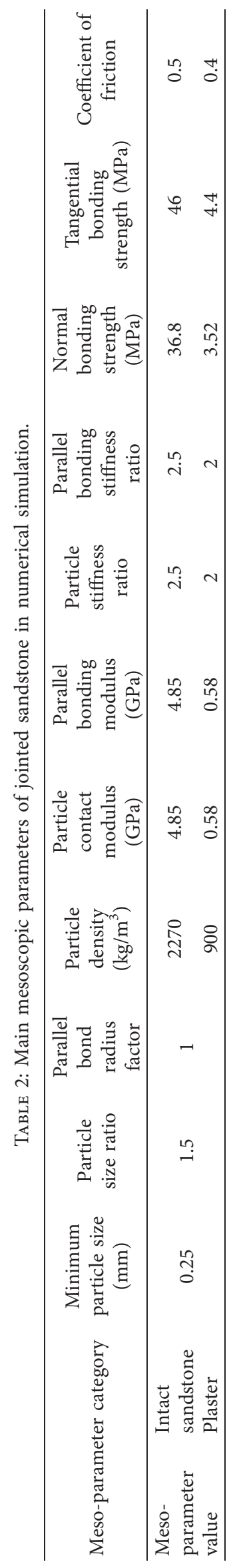


TABLE 3: Comparison of the calibration results for macroscopic mechanical parameters.

\begin{tabular}{lcccc}
\hline Material type & Test condition & Peak intensity $(\mathrm{MPa})$ & Elastic modulus $(\mathrm{GPa})$ & 7.01 \\
Rock & Laboratory test & 66.25 & 6.90 & 0.26 \\
& Numerical simulation & 66.63 & 0.85 & 0.25 \\
\hline \multirow{2}{*}{ Plaster } & Laboratory test & 6.6 & 0.84 & 0.30 \\
& Numerical simulation & 6.7 & 0.29 \\
\hline
\end{tabular}

element model under load, $E_{b}$; parallel bonding strain energy, $E_{\mathrm{pb}}$; linear contact strain energy, $E_{c}$; and dissipated energy, $E_{d}$, are calculated as follows:

$$
\begin{aligned}
E_{b} & =\sum_{N_{w}}\left(F_{i} \Delta U_{i}+M_{3} \Delta \theta_{3}\right), \\
E_{p b} & =\frac{1}{2} \sum_{N_{\mathrm{pb}}}\left(\left|\bar{F}_{i}^{n}\right|^{2} /\left(A \bar{k}^{n}\right)+\left|\bar{F}_{i}^{s}\right|^{2} /\left(A \bar{k}^{s}\right)+\left|\bar{M}_{3} /\left(I \bar{k}^{n}\right)\right|\right), \\
E_{c} & =\frac{1}{2} \sum_{N_{c}}\left(\left|\bar{F}_{i}^{n}\right|^{2} / \bar{k}^{n}+\left|\bar{F}_{i}^{s}\right|^{2} / \bar{k}^{s}\right), \\
E_{d} & =\sum_{N_{c}}\left(F_{i}^{s}\left(\Delta U_{i}^{s}\right)^{\text {slip }}\right), \\
\left(\Delta U_{i}^{s}\right)^{\text {slip }} & =\Delta U_{i}+\frac{\left(F_{i}^{s(t+\Delta t)}-F_{i}^{\mathrm{st}}\right)}{k^{s}},
\end{aligned}
$$

where $N_{w}$ is the number of walls; $F_{i}$ is the contact force between round particles; $\Delta U_{i}$ is the displacement of round particles; $M_{3}$ is the resultant moment of round particles; $\Delta \theta_{3}$ is the angle of round particles; $N_{\mathrm{pb}}$ is the total number of parallel bonds between particles; $A$ is the bonding area between particles; $\bar{k}^{n}$ and $\bar{k}^{s}$ are the average stiffness of the normal and tangential contact, respectively; $\overline{M_{3}}$ is the average resultant moment; $I$ is the particle moment of inertia; $N_{c}$ is the number of particles in contact; $\bar{F}_{i}^{n}$ and $\bar{F}_{i}^{s}$ are the average normal contact force and tangential contact force of the particles, respectively; $F_{i}^{s}$ is the tangential contact force between particles; $\left(\Delta U_{i}^{s}\right)^{\text {slip }}$ is the sliding displacement increment; and $k^{s}$ is the particle tangential contact stiffness.

PFC2D can monitor the entire meso-scale particle model in real-time, including the boundary energy, $E_{b}$; friction energy, $E_{\mu}$; damping energy, $E_{\beta}$; parallel bonding strain energy, $E_{\mathrm{pb}}$; particle strain energy, $E_{c}$; and kinetic energy, $E_{k}$. The total meso-strain energy, $E$, of the particle model is the boundary energy, $E_{b}$, and the elastic meso-strain energy, $E_{e}$, is composed of $E_{\mathrm{pb}}$ and $E_{c}$. The dissipated meso-energy, $E_{d}$, is calculated indirectly from the difference between $E$ and $E_{e}$. According to thermodynamic theory, the expression for the meso-energy relationship of jointed sandstone is as follows:

$$
E=E_{b}=E_{e}+E_{d}, E_{e}=E_{\mathrm{pb}}+E_{c}, E_{d}=E_{\mu}+E_{\beta},
$$

where $E, E_{e}$, and $E_{d}$ are three types of meso-energy that are divided by the area of the two-dimensional particle flow model to obtain the total meso-strain energy density, $M$, elastic meso-strain energy density, $M_{e}$, and dissipated mesoenergy density, $M_{d}$, respectively.
Based on the strain-hardening mechanism of intact rock before the peak presented by Zheng [33] and considering that the jointed sandstone is dominated by energy accumulation before the peak, the elastic strain energy is used as an example to establish the relationship between the elastic strain energy and the strain of the prepeak jointed sandstone. The nonlinear model is as follows:

$$
U_{e}=\frac{m}{1+e^{-n \varepsilon-\mathrm{mc}}} \text {. }
$$

\section{Macroenergy and Meso-Energy Damage Evolution Mechanism of Sandstone with Different Joint Forms under Uniaxial Compression}

The deformation and failure processes of jointed sandstone under uniaxial compression are accompanied by the transformation of various meso-energies. The evolution of the meso-energy can reflect the degradation process of the macroscopic rock mass structure and the final failure mode. A model sample with a joint dip angle $\alpha=45^{\circ}$ (joint length $2 a=1 \mathrm{~cm}$ ) is taken as an example to illustrate the mesoenergy conversion process of jointed sandstone.

As shown in Figure 6, the boundary energy increases exponentially before the peak. After reaching the peak point, the slope of the boundary energy curve decreases due to the rapid loss of rock mass structure strength. In the initial stage, almost all of the boundary energy is transformed into grain strain energy and parallel bonding strain energy. With continued loading, deformation and misalignment occur between the model particles. The increase in the particle strain energy and parallel bonding strain energy gradually becomes smaller than the increase in the boundary energy. The boundary energy is gradually transformed into friction energy, damping energy, and a small amount of kinetic energy between the particles. After reaching the peak point, the strain energy is rapidly released in the form of sound, heat, friction energy, and kinetic energy.

The microenergy conversion process of jointed sandstone is accompanied by the initiation and propagation of microcracks. During the loading process, the ratio of the number of microcracks, $\mathrm{C}$, to the total number of bonds, $\mathrm{C} 0$, in the model is the microscopic damage variable, $D$ [17]. As $C_{0}$ has a certain value, the change in the number of microcracks can be used to characterise the damage of the rock sample. A model sample with $\alpha=45^{\circ}$ and $2 a=1 \mathrm{~cm}$ is used to demonstrate the law.

As shown in Figure 7, as the load increases, the number of microcracks exhibits a horizontal development near zero 


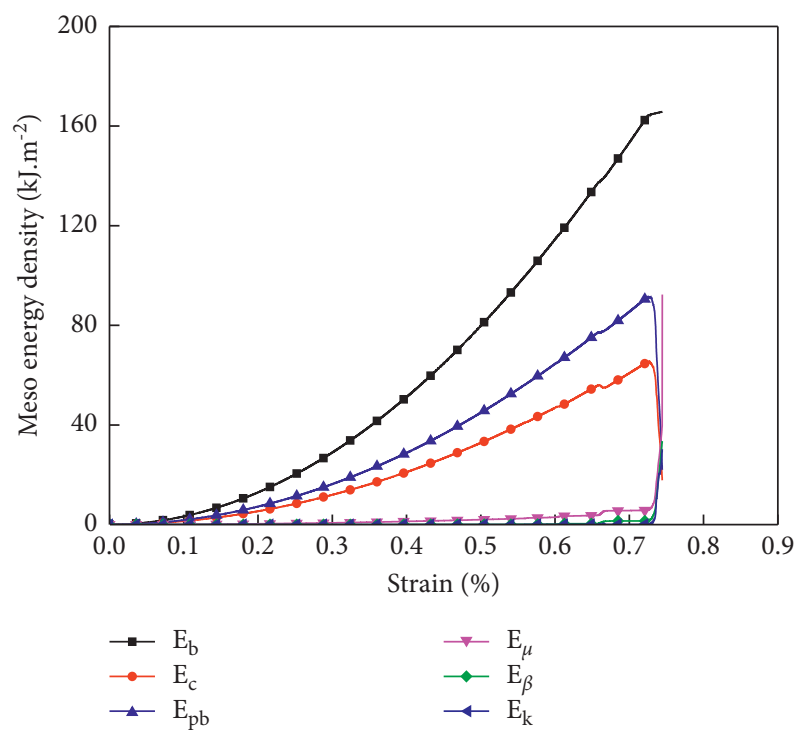

Figure 6: Mesoscopic energy conversion process of jointed sandstone.

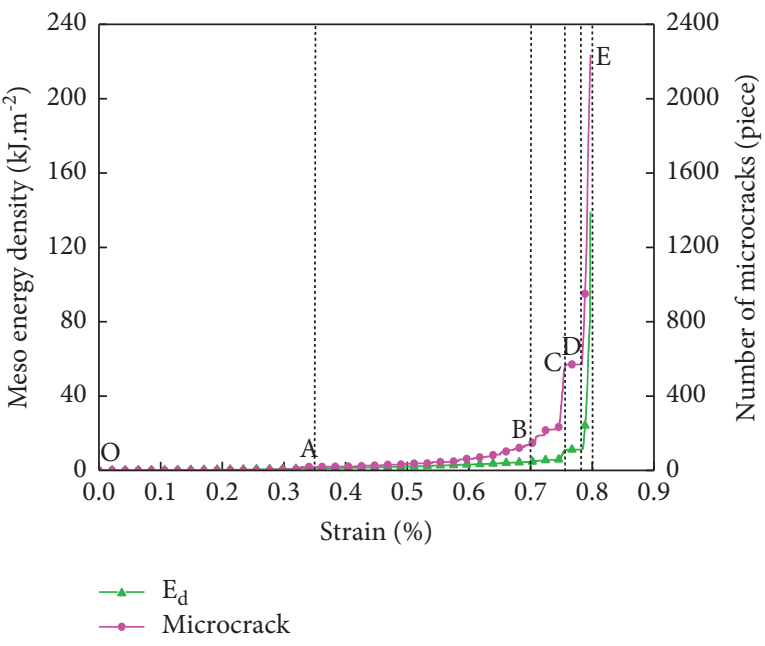

(a)

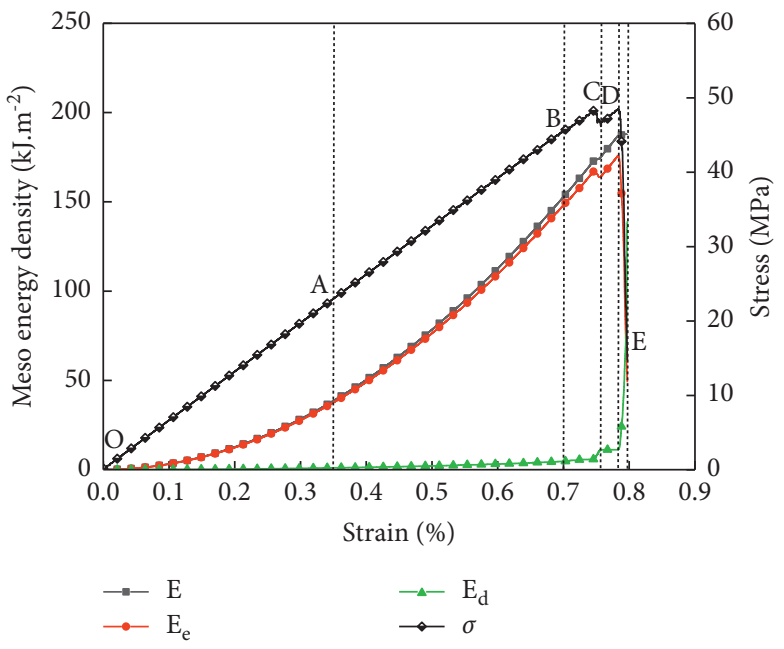

(b)

Figure 7: Meso-damage and energy evolution law in a single-jointed sandstone.

(OA section), a linear increase with a small slope $(\mathrm{AB}$ section), a sudden increase of different degrees (BC section), a concave increase (CD section), and a sudden increase during which the slope approaches infinity (DE section).

Compared with the macroscopic energy evolution process (Figure 8), the overall law is similar in the meso-level energy evolution process, with two key differences: (1) the meso-scale energy evolution process has no initial compaction energy dissipation period $\left(\mathrm{O}^{\prime} \mathrm{A}^{\prime}\right)$ and (2) the prepeak linear energy storage section $\left(\mathrm{A}^{\prime} \mathrm{B}^{\prime}\right)$ of the macroscopic energy evolution can be divided into a prepeak nondamage energy storage section (OA section) and stable damage energy low consumption section ( $\mathrm{AB}$ section) in the mesoscale energy evolution process.

Based on the stage characteristics of the meso-energy evolution of jointed sandstones, the characteristic values of the boundary points of the meso-energy evolution of jointed sandstones with different joint dip angles are calculated. As the occurrence of catastrophic damage in the $\mathrm{BC}$ section is a relatively short process, there is no need to consider the energy of point $C$. The relationship between the simulation results for different joint dip angles and the boundary points is shown in Figure 9.

The meso-energy values at the initiation, damage, and peak points of the jointed sandstone can reflect the energy accumulation during the entire loading process from no damage to initial damage, from no damage to sudden damage, and prepeak, respectively. As shown in Figure 9, as $\alpha$ increases, the meso-energy and characteristic stresses at the crack initiation point, damage point, peak point, and failure point all initially decrease and then increase. The moderately inclined jointed sandstone reaches the meso- 


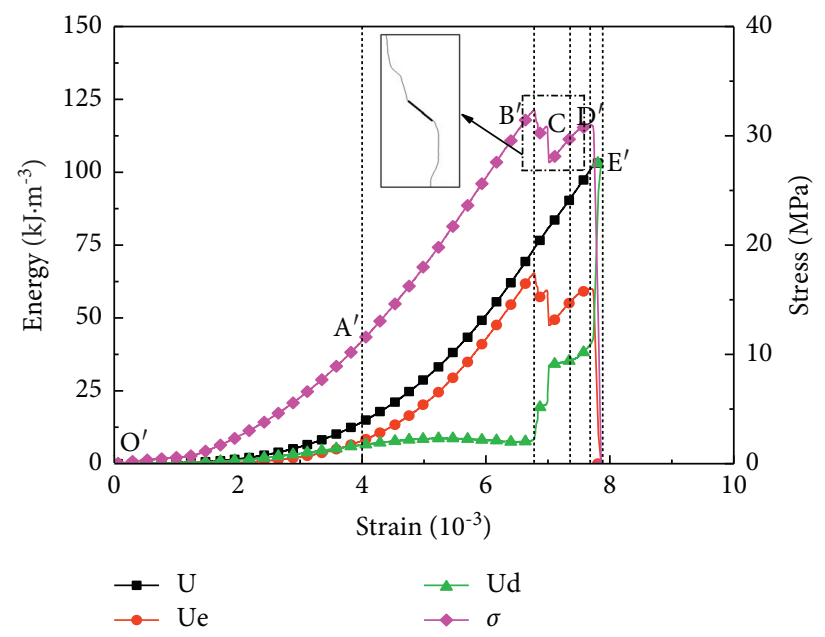

FIgURe 8: Macroscopic energy evolution law of jointed sandstone [9].

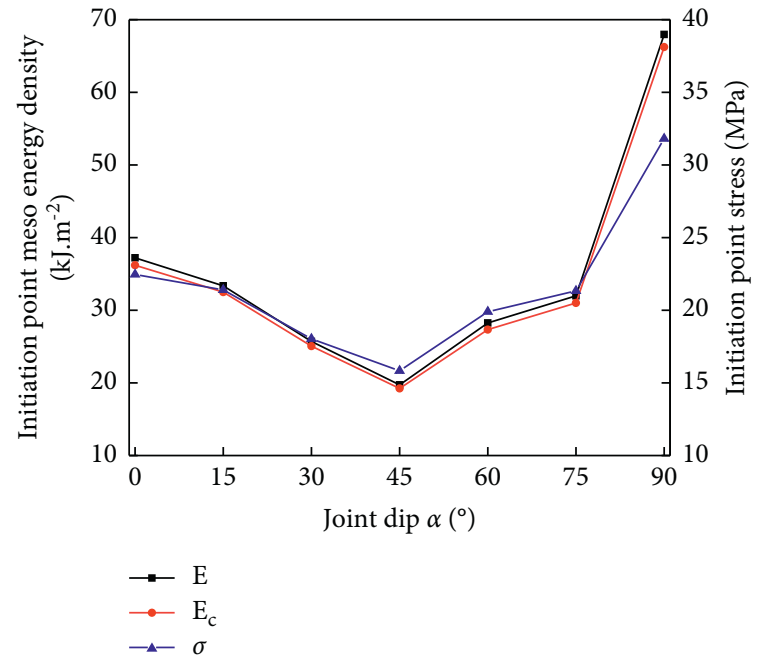

(a)

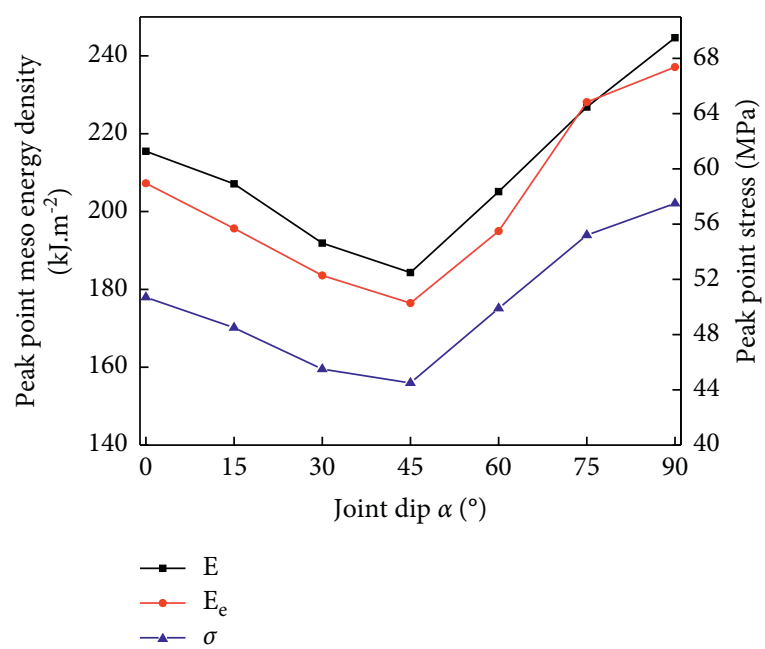

(c)

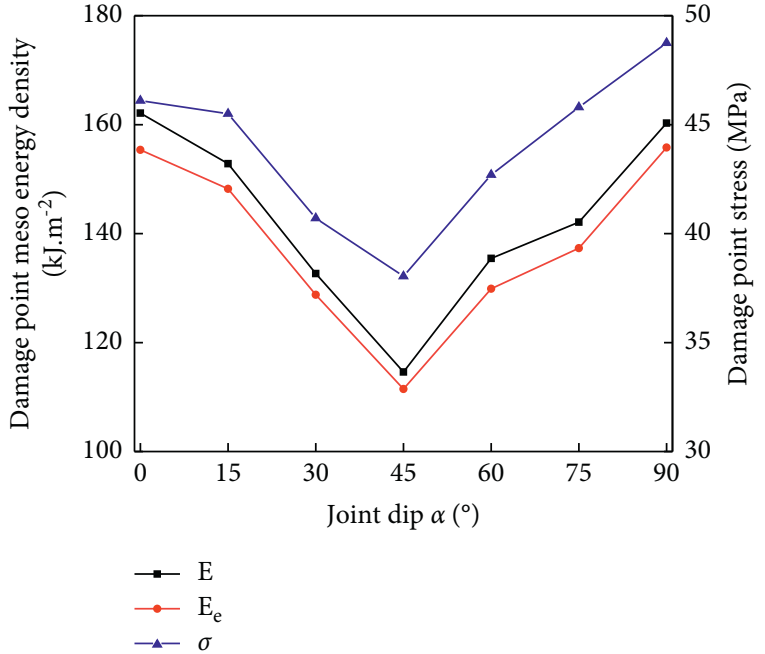

(b)

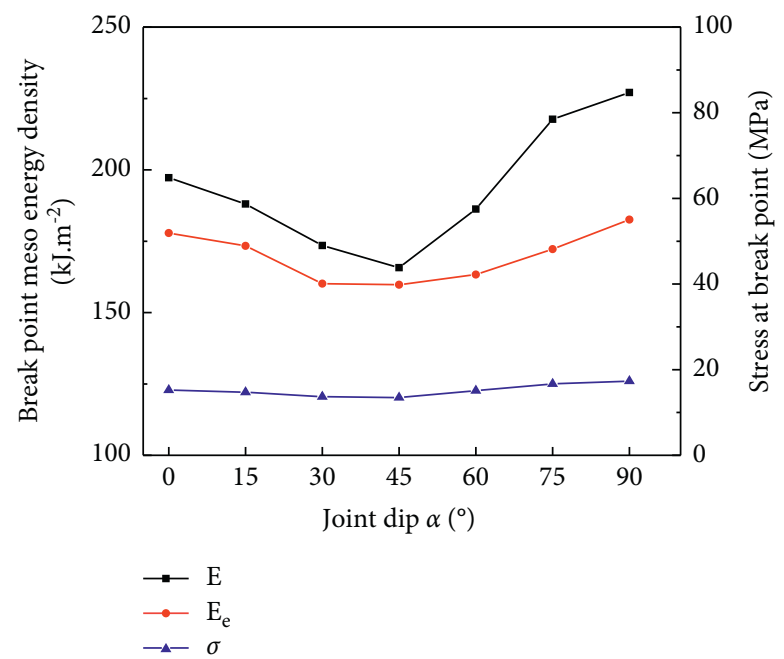

(d)

FIGURE 9: Relationship between the mesoscopic energy and stress at each boundary point and the joint dip angle: (a) initiation point, (b) damage point, (c) peak point, and (d) break point. 
energy characteristic point first. The corresponding postpeak mutation damage is relatively slight, followed by progressive damage after the peak; the jointed sandstone with a gradual dip is the second-best, and the jointed sandstone with a steep dip exhibits the most severe damage. From the crack initiation point to the damage point and then the peak point, the difference between the total meso-strain energy and the elastic meso-strain energy gradually increases. The dissipated meso-energy range at the crack initiation point is between 0.49 and $1.74 \mathrm{~kJ} \cdot \mathrm{m}^{-2}$, at the damage point, it is between 3.12 and $6.74 \mathrm{~kJ} \cdot \mathrm{m}^{-2}$, and at the peak point, it is between 7.53 and $11.46 \mathrm{~kJ} \cdot \mathrm{m}^{-2}$. In other words, as the load increases, the input energy is gradually transformed into dissipated meso-energy, and the rock structure gradually produces cumulative damage. To study the severity of the failure of jointed sandstone during the loading process, the failure mode, and effect of the joint dip angle of the mesodamage situation, the numerical simulation results at the failure point (where the peak point and postpeak stress level are $70 \%$ of the peak stress) are analysed, as shown in Figure 10.

As shown in Figure 10(a), as $\alpha$ increases, the sudden increase in the dissipated energy of postpeak jointed sandstone and the sudden decrease in elastic strain energy all show an asymmetric V-shape characterised by an initial decrease followed by an increase; the greater the magnitude of the meso-energy mutation after the peak of the jointed sandstone is, the more severe the damage after the peak will be. As shown in Figure 10(b), as $\alpha$ increases, the prepeak cumulative meso-damage level initially increases and then decreases. As shown in Figure 11, the number of tensile cracks at the characteristic energy point of the jointed sandstone is significantly greater than the number of shear cracks. As $\alpha$ increases, the number of shear cracks initially decreases and then increases. In Figure 12, red colour indicates the joint, yellow indicates tensile cracks, and purple indicates shear cracks. The number of microcracks in the jointed sandstone increases with an increase in the load. The microcracks in the sandstone with $\alpha=0^{\circ}$ initiate from the inside of the joint, gradually expand to the middle, and expand from the top and bottom of the left tip of the joint to the top and bottom of the right tip, resulting in a nearly $\mathrm{X}$-shaped tensile-shear mixed failure. The microcracks in the sandstone with $\alpha=45^{\circ}$ start from the inside of the joint and gradually expand to the joint tip in the direction of approximately $45^{\circ}$, resulting in shear failure. The microcracks in the sandstone with $\alpha=90^{\circ}$ are less affected by the prefabricated joints. The microcracks are distributed more uniformly after initiation and then gradually expand at the upper left of the joint; in addition, secondary microcracks initiate at the lower right of the joint, causing splitting failure.

Figure 13 shows the maximum principal strain cloud diagram of jointed sandstone filled with gypsum under three joint dip angles obtained by DIC, it can be seen from the figure that it is basically consistent with the microcrack distribution characteristics at the peak point of the numerical simulation. This result further explains the rationality of the numerical model.
The change in each energy index value at the peak point with varying joint dip angles obtained from the test data is shown in Figure 14. The PFC numerical simulation results can better reflect the variation trend of the test data. Comparing the data obtained from the PFC numerical simulation with the experimental data, the error analysis results are summarised in Table 4.

As indicated in Table 4, the relative error between the uniaxial compressive strength obtained by the test and the uniaxial compressive strength obtained by the PFC is small, indicating that the PFC numerical simulation can better reflect the test situation and has a higher reliability.

To investigate the effect of the joint length at each mesoenergy characteristic point of the jointed sandstone, based on the numerical simulation results, the eigenvalues of the boundary points are calculated at each stage of the mesoenergy evolution of the jointed sandstone with different joint lengths. The relationship between the meso-energy and the characteristic stress of the sandstone energy characteristic points with varying joint lengths is shown in Figure 15.

As shown in Figure 15, as the joint length, $2 a$, increases, the meso-energy and stress at the initiation point decrease approximately linearly, whereas the meso-energy, damage stress, and peak stress at the damage point and peak point decrease exponentially with a decreasing slope. In other words, the degradation effect decreases with an increase in $2 a$. The characteristic energy of the crack initiation point and the degradation of the stress are significantly affected by the joint length.

The characteristic curves of the meso-damage and postpeak failure of sandstones with different joint lengths are shown in Figure 16. The sudden increase in postpeak dissipated meso-energy and sudden decrease in elastic meso-strain energy decrease exponentially with the increase in joint length. The prepeak cumulative mesodamage level increases with an increase in $2 a$, and the postpeak mutation meso-damage level exhibits the opposite trend. The larger $2 a$ is, the greater the initial damage degree is and the smaller the corresponding postpeak energy mutation amplitude will be; the final degree of cracking is determined by the cumulative damage before the peak. It can be seen from Figure 17 that the proportion of tensile cracks at the time of failure is $59.04 \%$ to $62.49 \%$, indicating that the length of the joint does not significantly affect the final failure mode of the sandstone. It can be seen from Figure 18 that sandstone cracks with different joint lengths all expand outward from the prefabricated cracks, there are secondary shear cracks locally, and final shear failure is dominant. The larger the value of $2 a$, the smaller the expansion range of the crack initiation point is (smaller energy required for initiation), the larger the crack propagation range at the peak point will be (faster crack development process), and the smaller the crack mutation after the peak will be (slower failure after the peak).

Figure 19 shows the maximum principal strain cloud diagram of the sandstone filled with gypsum under three joint dip angles obtained by DIC. It can be seen from the figure that the distribution of microcracks at the peak point of the numerical simulation is basically consistent. 


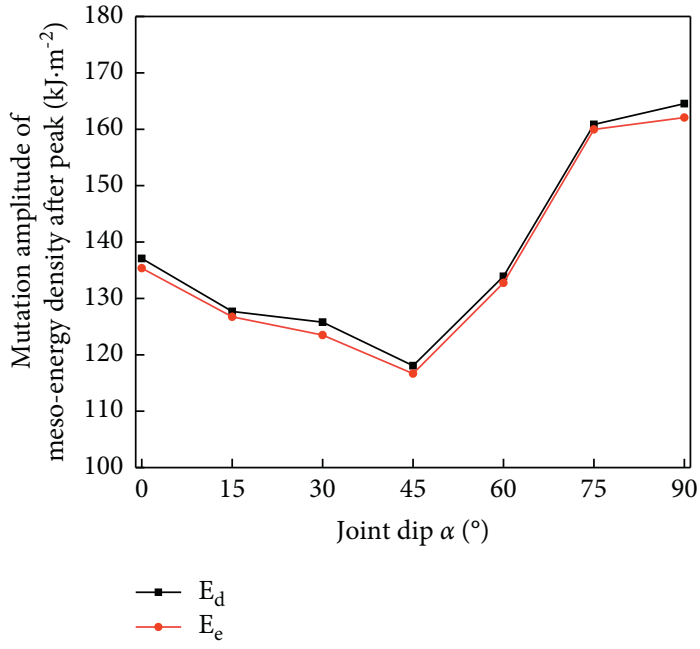

(a)

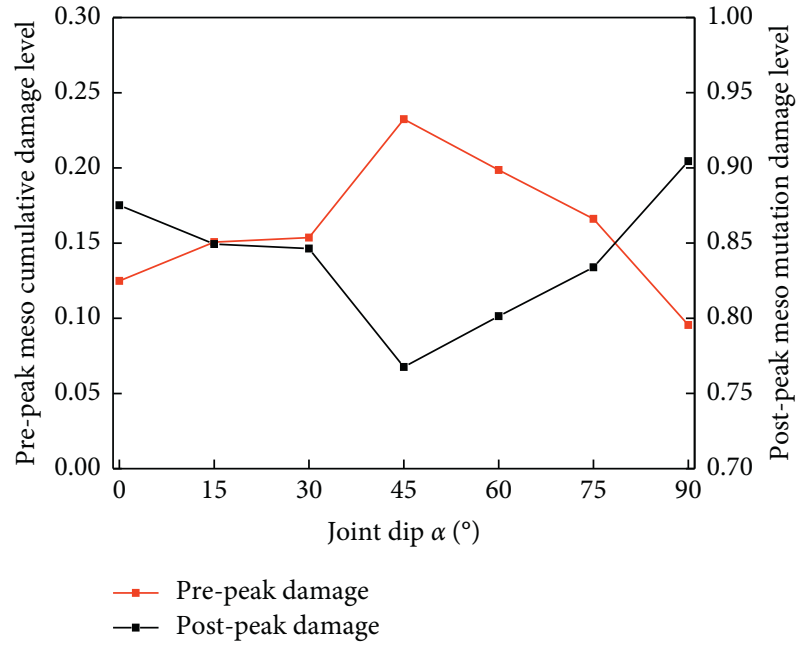

(b)

FIGURE 10: Relationship between the abrupt change in meso-energy and meso-damage level before and after the peak of jointed sandstone with varying $\alpha$.

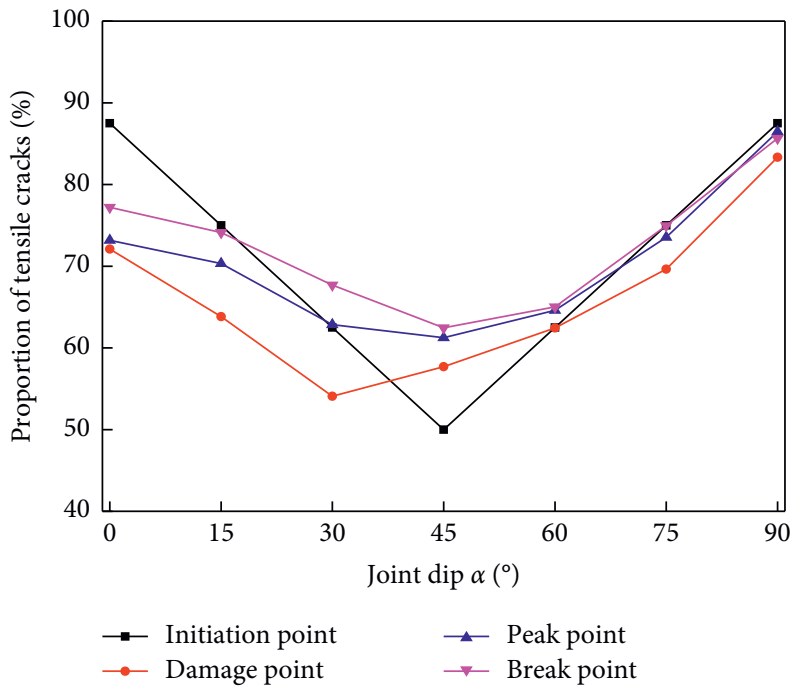

FIgURE 11: Relationship between the tensile and shear joints and joint dip angle at the energy feature points.

The variation in each energy index at the peak point with the length of the joint obtained from the experimental data is shown in Figure 20. From the figure, it can be seen that the variation in the energy density with the joint length obtained in the experiments is consistent with that obtained in the PFC numerical simulation. Comparing the data obtained from the PFC numerical simulation with the experimental data, the error analysis results are summarised in Table 5.

From the error analysis results in Table 5, although the PFC numerical simulation results and the test results have a large error when the joint length is $3 \mathrm{~cm}$, overall, the remaining errors are still small, which also shows that PFC can more accurately reflect the test situation.

\section{Meso-Energy Damage Evolution Mechanism of Jointed Sandstone under Biaxial Compression}

Based on the results of the laboratory uniaxial compression tests and the meso-parameter calibration for jointed sandstone, PFC is used to carry out numerical simulations of jointed sandstone under biaxial compression. The stressstrain curves for jointed sandstones with a joint dip of $60^{\circ}$ $(2 a=1 \mathrm{~cm})$ and a joint length of $1.5 \mathrm{~cm}\left(\alpha=45^{\circ}\right)$ under different confining pressures are shown in Figure 21 as an example for analysis.

As shown in Figure 21, the stress-strain curves of the jointed sandstones under different confining pressures are 


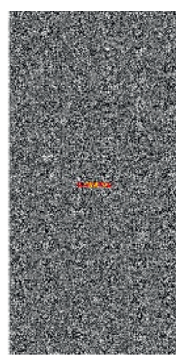

A

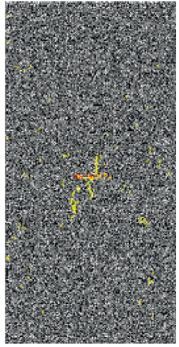

B

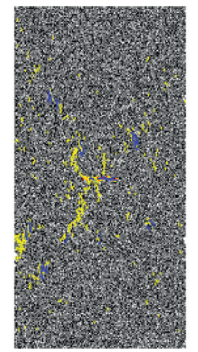

$\mathrm{D}$

(a)

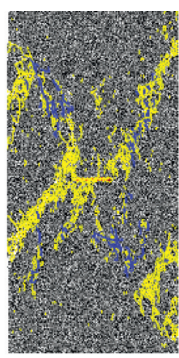

$\mathrm{E}$

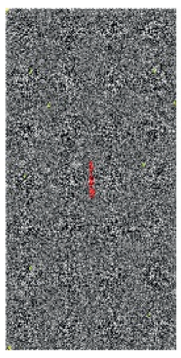

A

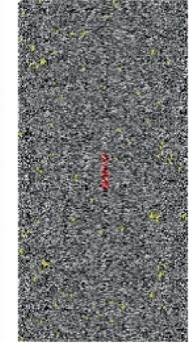

B

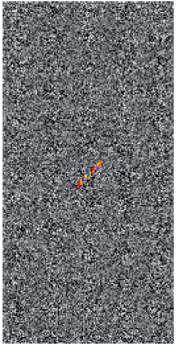

A

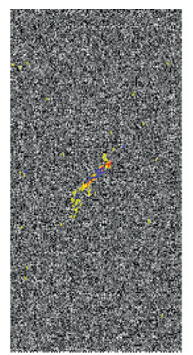

$\mathrm{B}$
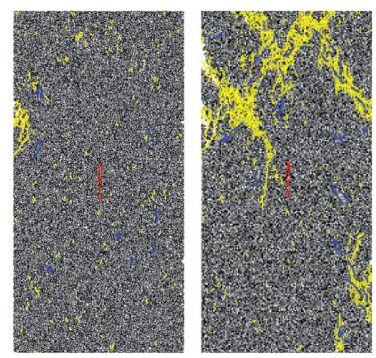

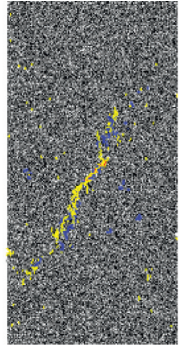

$\mathrm{D}$

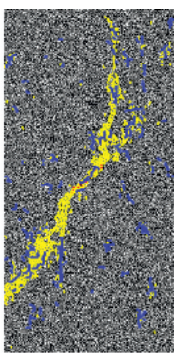

$\mathrm{E}$

(b)

E

(c)

FIGURE 12: Microcrack distribution characteristics of jointed sandstone at energy feature points with different $\alpha$ : (a) $\alpha=0^{\circ}$, (b) $\alpha=45^{\circ}$, (c) $\alpha=90^{\circ}$ (A is the initiation point, $\mathrm{B}$ is the damage point, $\mathrm{D}$ is the peak point, and $\mathrm{E}$ is the failure point).

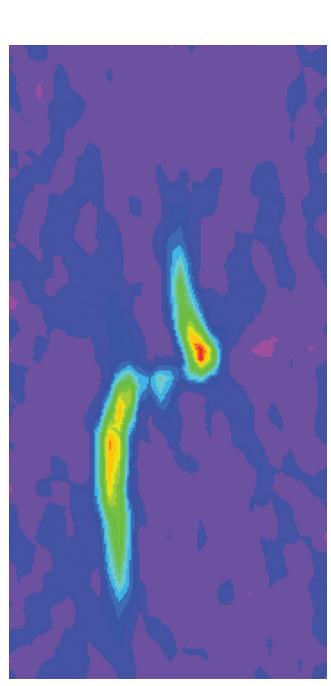

(a)

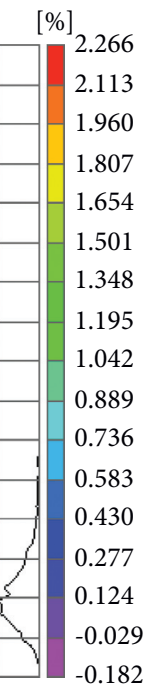

$-0.182$

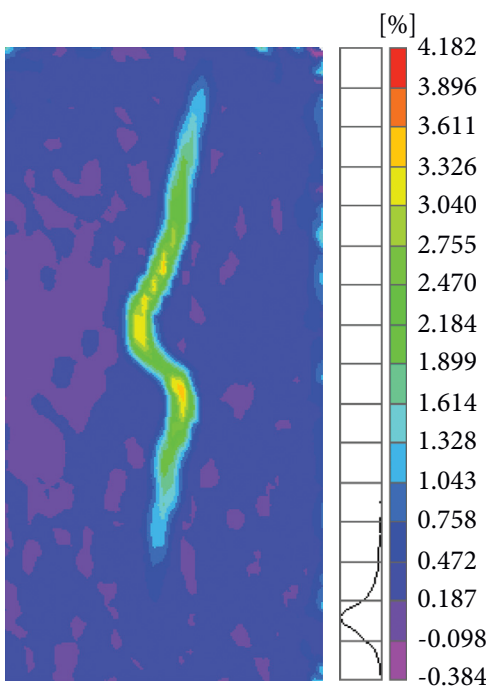

(b)

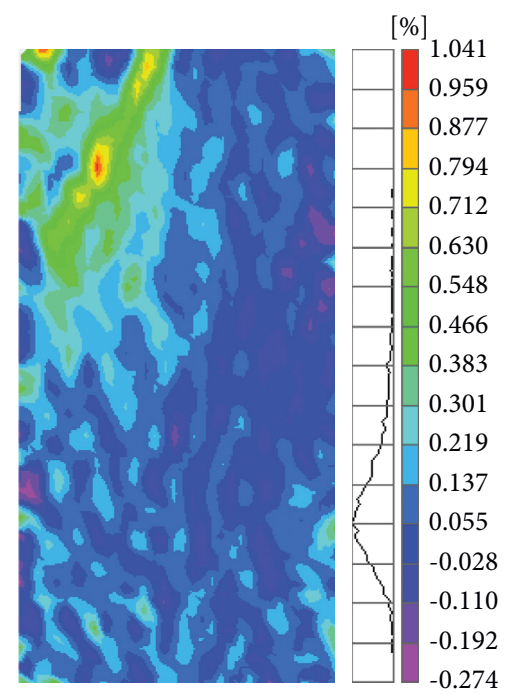

(c)

FIGURE 13: Maximum principal strain field of jointed sandstone peaks with different joint dip angles: (a) $\alpha=0^{\circ}$, (b) $\alpha=45^{\circ}$, and (c) $\alpha=90^{\circ}$.

approximately coincident in the elastic deformation stage, which indicates that the average elastic modulus of jointed sandstone in the elastic stage is not affected by $\sigma_{3}$; this result is consistent with the test results reported by You [34]. As $\sigma_{3}$ increases, there is no obvious stress drop before the peak in the jointed sandstone, the yield weakening stage gradually becomes obvious, and the peak strength and peak strain gradually increase. In other words, a larger $\sigma_{3}$ will cause the prepeak deformation and damage process of the jointed sandstone to be more stable, and the toughness and strength of the jointed sandstone will be significantly enhanced. The postpeak stress drop of the jointed sandstone gradually slows with the increase in $\sigma_{3}$, and the larger the $\sigma_{3}$ is, the higher the residual strength will be. The meso-energy evolution curves of sandstone with $\alpha=60^{\circ}$ and $2 a=1 \mathrm{~cm}$ under different $\sigma_{3}$ conditions are used as an example to further discuss the meso-energy evolution characteristics of jointed sandstone under different confining pressures, as shown in Figure 22. 


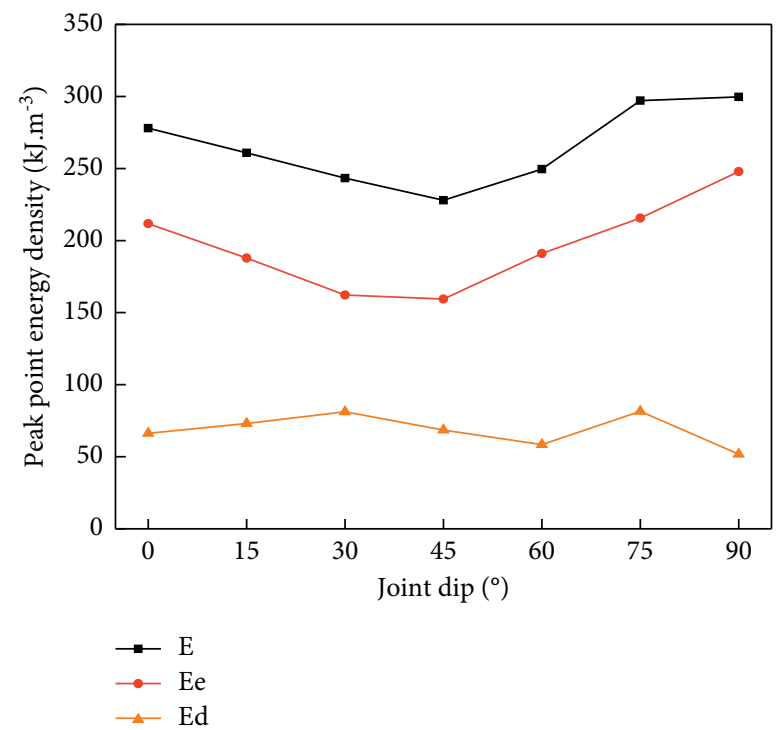

FIGURE 14: Relationship between energy at the peak point and the joint dip angle in jointed sandstone.

TABLE 4: Comparison of PFC numerical simulation results and test results of uniaxial compressive strength varying with inclination angle.

\begin{tabular}{lccc}
\hline Joint dip $\left(\alpha\left(^{\circ}\right)\right)$ & Uniaxial compressive strength of test $(\mathrm{MPa})$ & Uniaxial compressive strength of PFC (MPa) & Relative error $(\%)$ \\
\hline 0 & 50.86 & 50.7 & 0.314589 \\
15 & 48.72 & 48.5 & 0.45156 \\
30 & 46.22 & 45.5 & 1.557767 \\
45 & 44.93 & 44.5 & 0.957044 \\
60 & 50.62 & 49.9 & 1.422363 \\
75 & 55.32 & 55.2 & 0.21692 \\
90 & 57.71 & 57.5 & 0.363888 \\
\hline
\end{tabular}

As shown in Figure 22, the meso-energy conversion processes of jointed sandstone under different confining pressures have a certain similarity. When the stress is in the elastic deformation stage, the meso-energy increases, the total meso-strain energy absorbed by the jointed sandstone is mainly transformed into elastic meso-strain energy, and the dissipated energy is relatively small. When the stress transitions from the weakening stage to the peak strength, the dissipation energy curve increases in a concave shape. During the process from the peak point to the failure point, the jointed sandstone begins to fail internally, resulting in an obvious macroscopic fracture surface. At this time, the elastic strain energy decreases rapidly, the dissipation energy increases, and more energy is converted into dissipation energy. Based on the numerical simulation results, the peak strengths of sandstone with different joint dip angles and lengths under varying $\sigma_{3}$ are analysed, as shown in Figure 23.

As shown in Figure 23, as $\alpha$ increases, the peak strengths of jointed sandstones with different $\sigma_{3}$ exhibit a U-shaped change, which is consistent with the experimental results reported by Chen et al. [35]. As $2 a$ increases, the peak strengths of sandstones with different $\sigma_{3}$ gradually decrease. This reveals that the joint dip angle and joint length still affect the mechanical anisotropy of jointed sandstones under different confining pressures. Therefore, it is necessary to investigate the characteristics of the joint dip effect and joint length effect on the meso-energy evolution mechanism of jointed sandstones under different confining pressures. The meso-energy evolution characteristics at the peak points for sandstones with different joint dip angles under varying $\sigma_{3}$ are shown in Figure 24.

As shown in Figure 24, as $\sigma_{3}$ increases, the meso-energy at the peak points gradually increase for sandstones with different $\alpha$, and the proportion of elastic energy gradually decreases. That is, when $\sigma_{3}$ is greater, more energy needs to be input from the outside before the peak of the jointed sandstone. The increase in the energy storage limit of the rock mass is accompanied by an increase in the energy consumption mechanism. The elastic meso-strain energy can effectively characterise the energy storage capacity of jointed sandstones in the prepeak stage; therefore, the relationship between $\sigma_{3}$ at the peak point and the elastic mesostrain energy of sandstones at each joint dip angle is fitted using the equation $y=a+b \sigma_{3}$; the fitting results are shown in Figure 25. As shown in Figure 25, $\sigma_{3}$ has a good linear correlation with the elastic meso-strain energy of jointed sandstone, which is consistent with the results reported by Wen et al. [36]. Here, $y$ represents the elastic meso-strain energy accumulated at the peak point, and $a$ represents the meso-elastic strain energy at the peak point under uniaxial compression. The meso-elastic strain energy at the peak point initially decreases and then increases as $\alpha$ increases, 


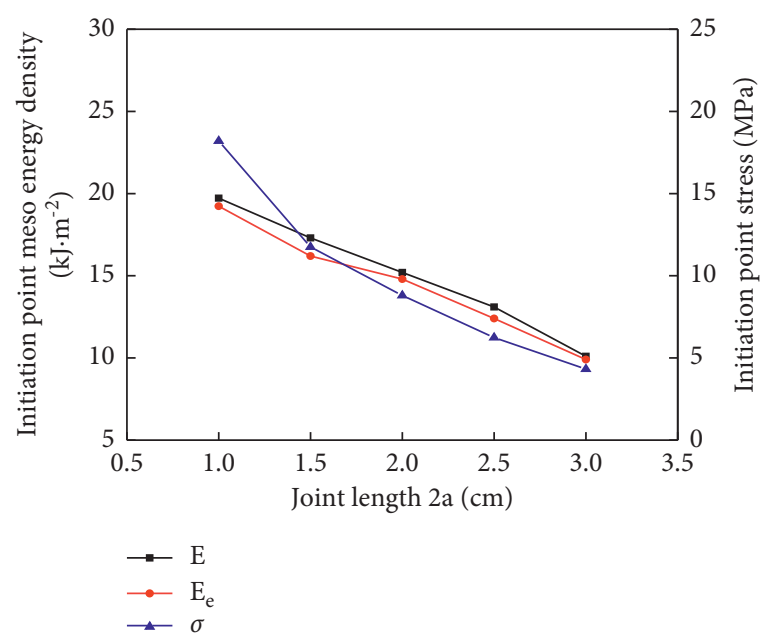

(a)

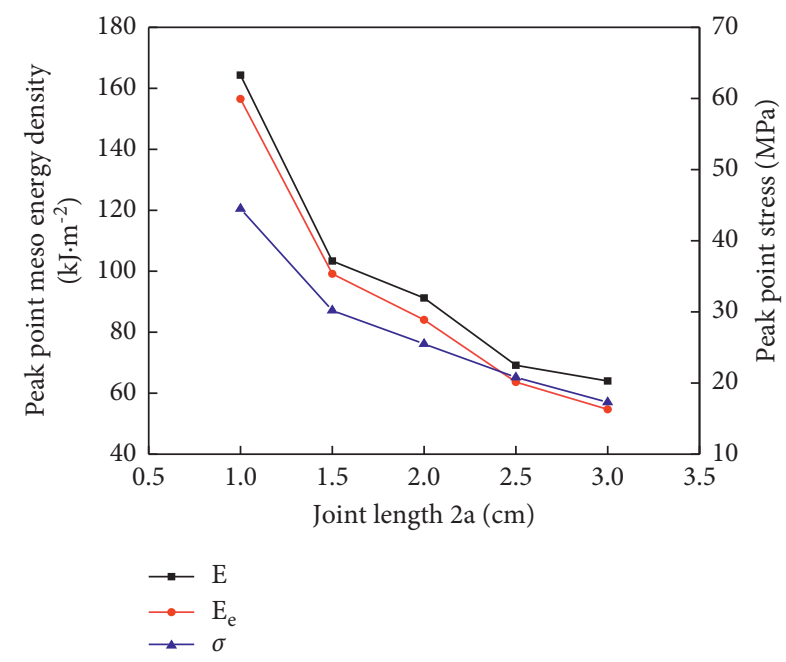

(c)

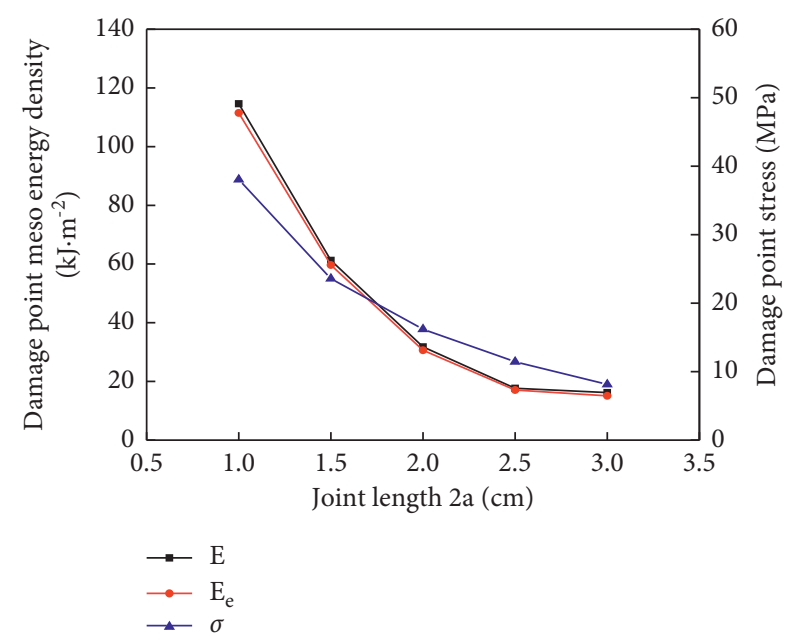

(b)

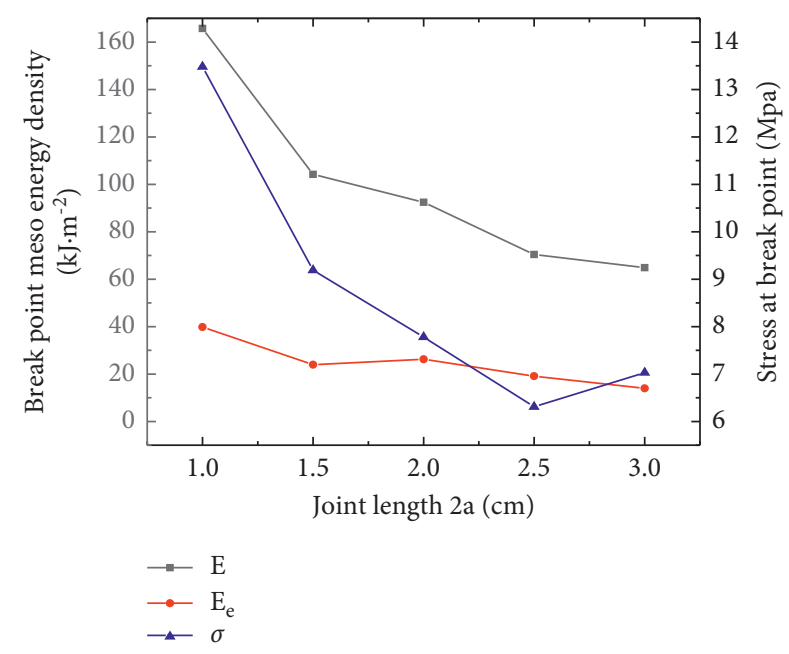

(d)

FIGURE 15: Characteristic point meso-energies with varying joint lengths: (a) initiation point, (b) damage point, (c) peak point, and (d) break point.

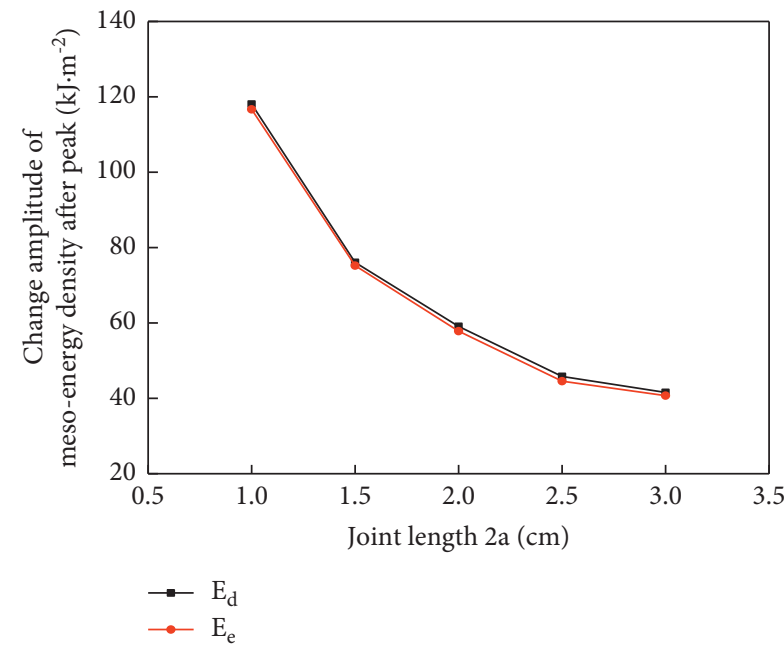

(a)

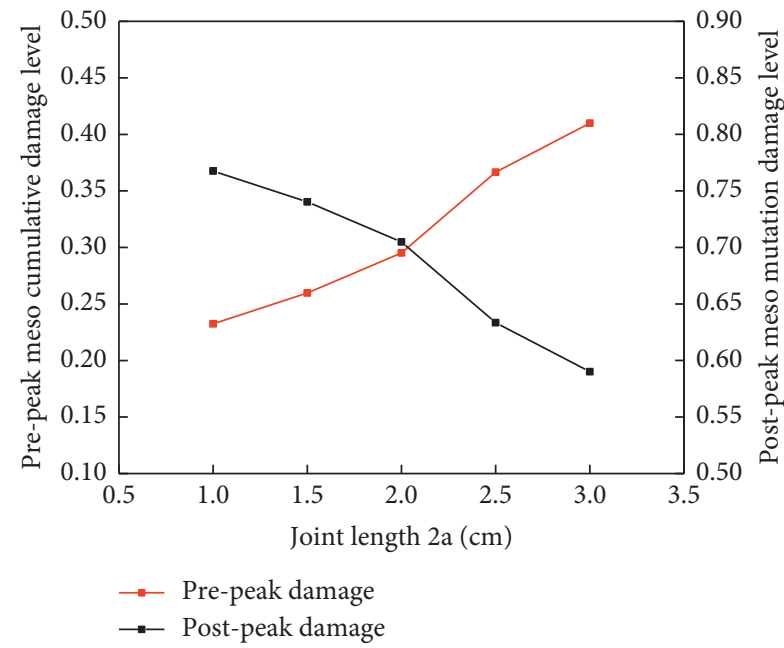

(b)

FIGURE 16: Variation in the amplitude of the abrupt change in the meso-energy after the peak and meso-damage level before and after the peak with varying joint lengths. 


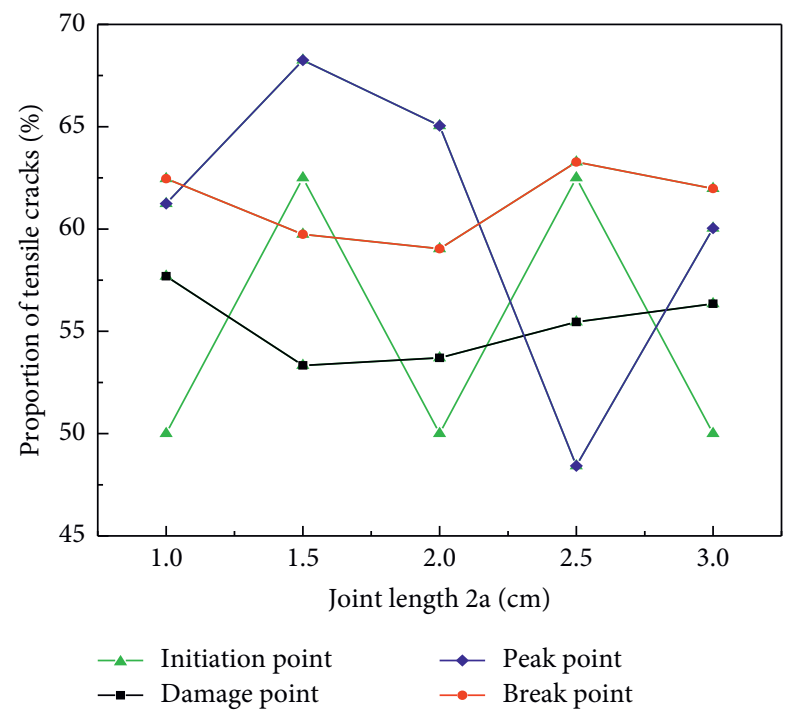

Figure 17: Relationship between tensile cracks and the joint dip angle at energy characteristic points.

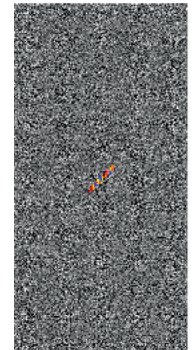

A

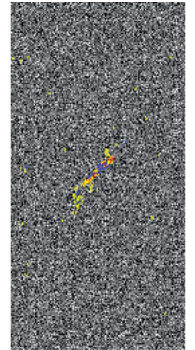

B

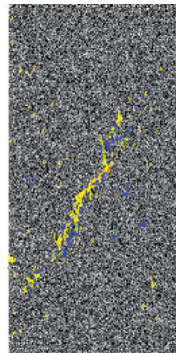

D

(a)

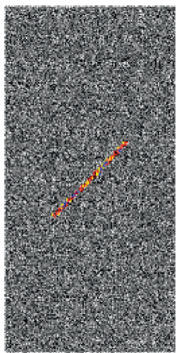

A

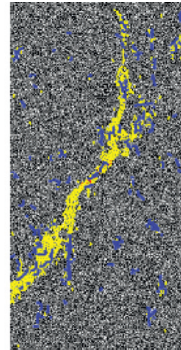

E

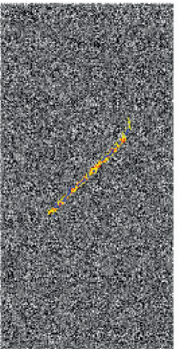

B

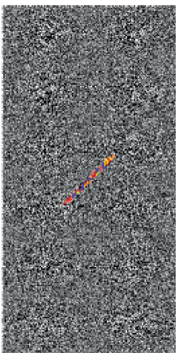

A

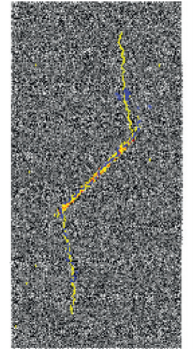

D

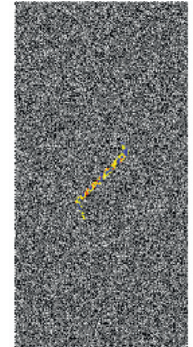

B

(b)

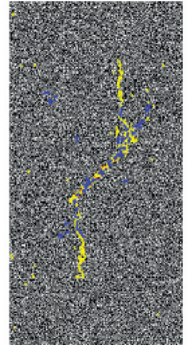

D

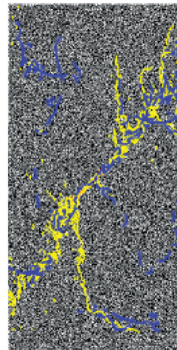

E

(c)

FIGURE 18: Distribution characteristics of microcracks at energy characteristic points of jointed sandstones with varying joint lengths: (a) $2 a=1 \mathrm{~cm}$, (b) $2 a=2 \mathrm{~cm}$, and (c) $2 a=3 \mathrm{~cm}$ (A is the initiation point, B is the damage point, D is the peak point, and $\mathrm{E}$ is the failure point).

and the larger the $\sigma_{3}$ is, the more obvious the anisotropy of the effect of $2 a$ on the elastic strain energy at the peak point of the jointed sandstone will be. In the fitting equation, $b$ represents the degree of influence of $\sigma_{3}$ on the accumulation of elastic strain energy at the peak point. The larger the $b$ is, the faster the accumulation of elastic meso-strain energy will be when $\sigma_{3}$ is constant. As $\alpha$ increases, $b$ initially decreases and then increases, and $b$ is greater for the steeply inclined sandstone than the gently inclined sandstone.
The postpeak energy evolution of jointed sandstone can reflect its deformation and failure characteristics. For example, Song et al. [37] considered both the prepeak energy accumulation and postpeak energy release to evaluate rock brittleness. Figure 26 shows the meso-energy mutation after the sandstone peak with different values of $\alpha$ under varying $\sigma_{3}$.

As shown in Figure 26, as $\sigma_{3}$ increases, the postpeak meso-energy at the failure points gradually increases for sandstones with different $\alpha$, which indicates that the 


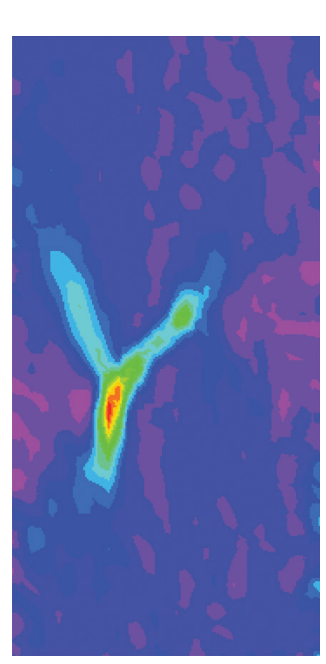

(a)
[\%]

\begin{tabular}{|l|l}
\hline & 3.040 \\
2.823 \\
2.607 \\
2.390 \\
2.173 \\
1.957 \\
1.740 \\
1.523 \\
1.307 \\
1.090 \\
0.873 \\
0.656 \\
0.440 \\
0.223 \\
0.006 \\
-0.210 \\
-0.427
\end{tabular}

$-0.427$

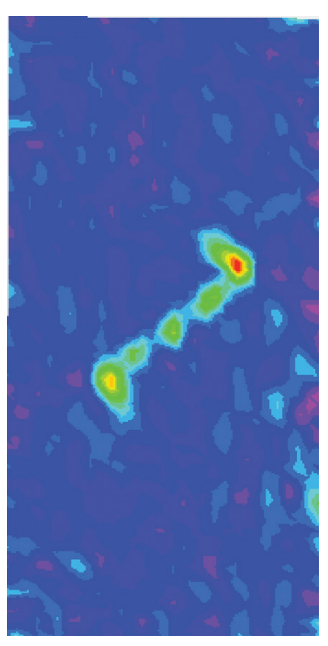

(b)
[\%]

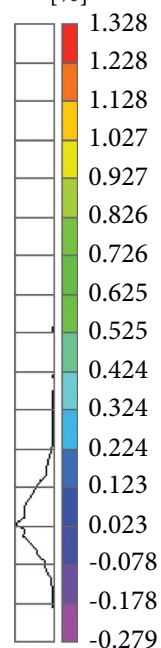

$-0.279$

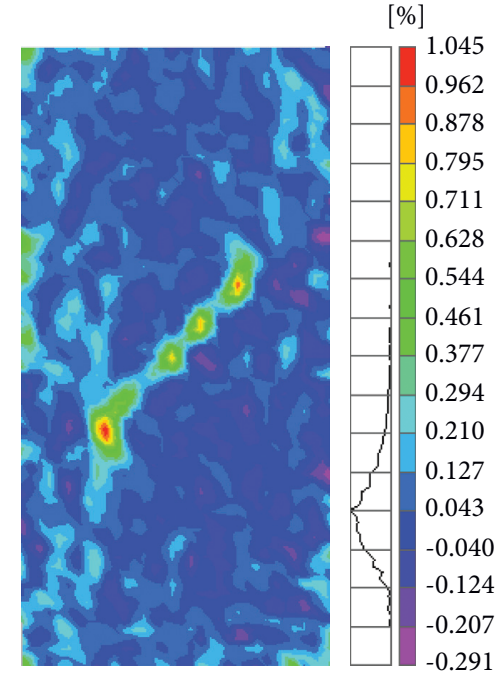

(c)

FIGURE 19: Maximum principal strain field at peak points of jointed sandstones with different joint lengths: (a) $2 a=1 \mathrm{~cm}$, (b) $2 a=2 \mathrm{~cm}$, and (c) $2 a=3 \mathrm{~cm}$.

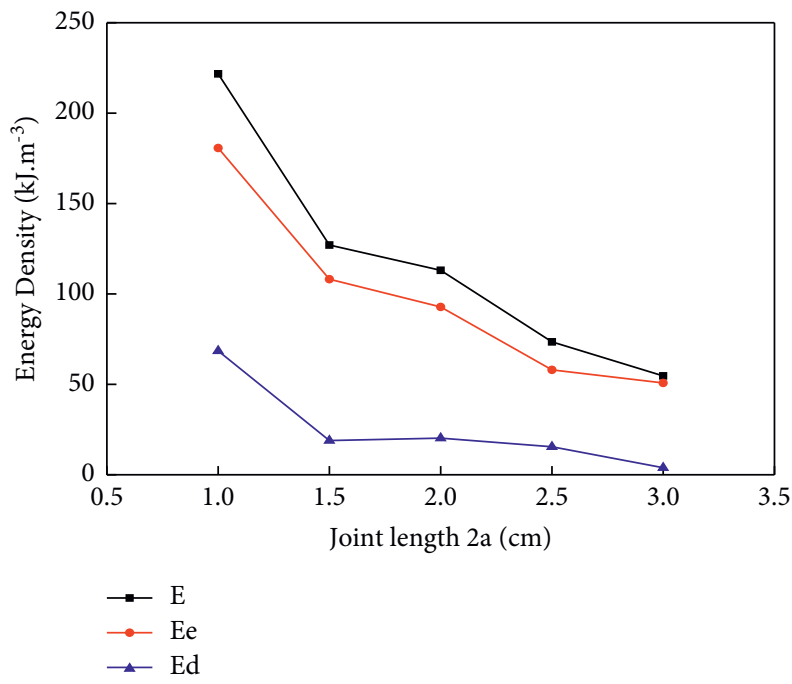

FIGURE 20: Relationship between the peak point energy of jointed sandstone and joint length.

TABLE 5: Comparison of PFC numerical simulation results and experimental results of uniaxial compressive strength varying with joint length.

\begin{tabular}{lccc}
\hline Joint length $\left(\alpha\left(^{\circ}\right)\right)$ & Uniaxial compressive strength of test $(\mathrm{MPa})$ & Uniaxial compressive strength of PFC (MPa) & Relative error $(\%)$ \\
\hline 1 & 44.41 & 44.5 & 0.202247 \\
1.5 & 30.09 & 30.2 & 0.364238 \\
2 & 26.97 & 25.5 & 5.450501 \\
2.5 & 20.98 & 20.8 & 0.85796 \\
3 & 16.88 & 19.3 & 12.53886 \\
\hline
\end{tabular}

inhibition of $\sigma_{3}$ will significantly increase the energy at the failure point of the jointed sandstone; this is consistent with the test results reported by Zhang and Gao [10]. It can be seen from the figure that the elastic meso-strain energy suddenly decreases, and the dissipated meso-energy suddenly increases; with an increase in $\sigma_{3}$, the magnitude of the sudden change in the meso-energy after the peak decreases for sandstones with different $\alpha$. The relationship between the sudden decrease in the elastic meso-strain energy and the sudden increase in the dissipated meso- 


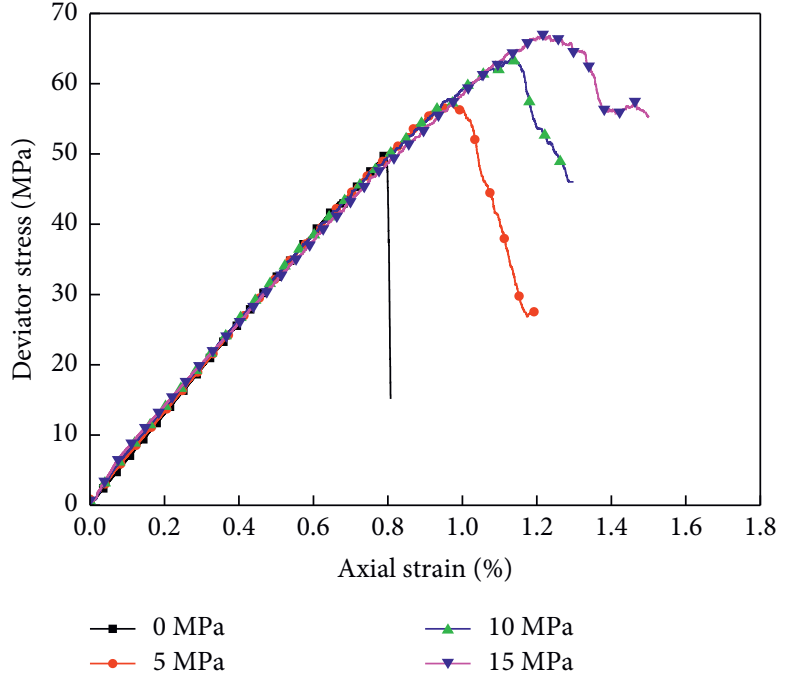

(a)

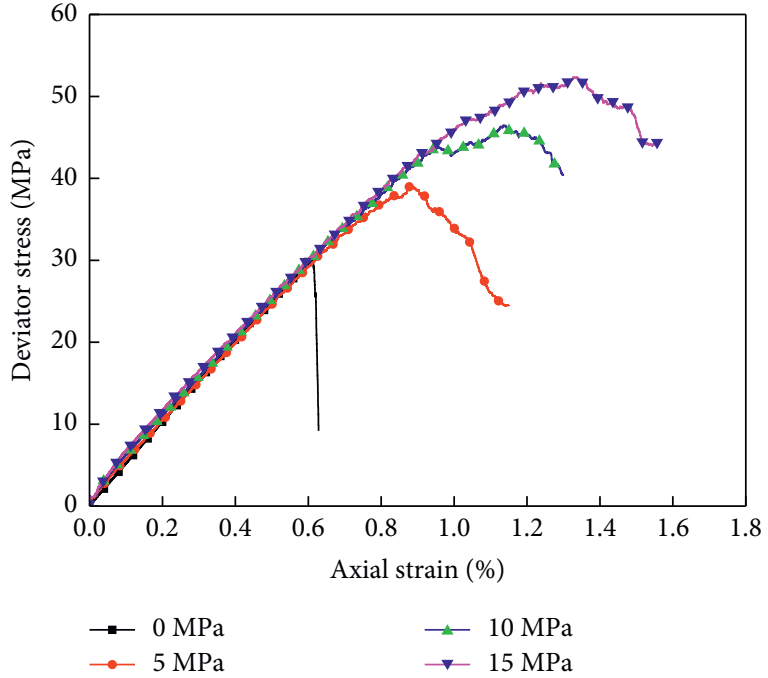

(b)

FIgURE 21: Stress-strain curves of jointed sandstones under different confining pressures.

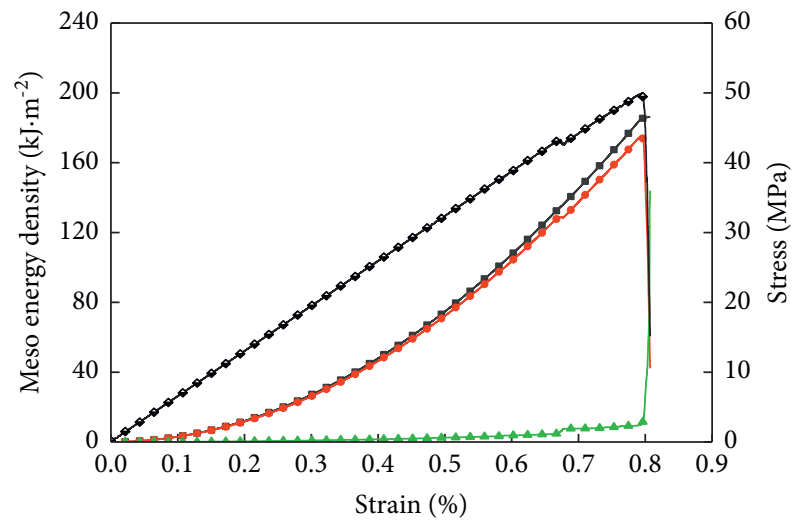

$$
\begin{aligned}
& -\mathrm{E} \\
& \rightarrow-\mathrm{E}_{\mathrm{e}}
\end{aligned}
$$$$
\rightarrow \mathrm{E}_{\mathrm{d}}
$$

(a)
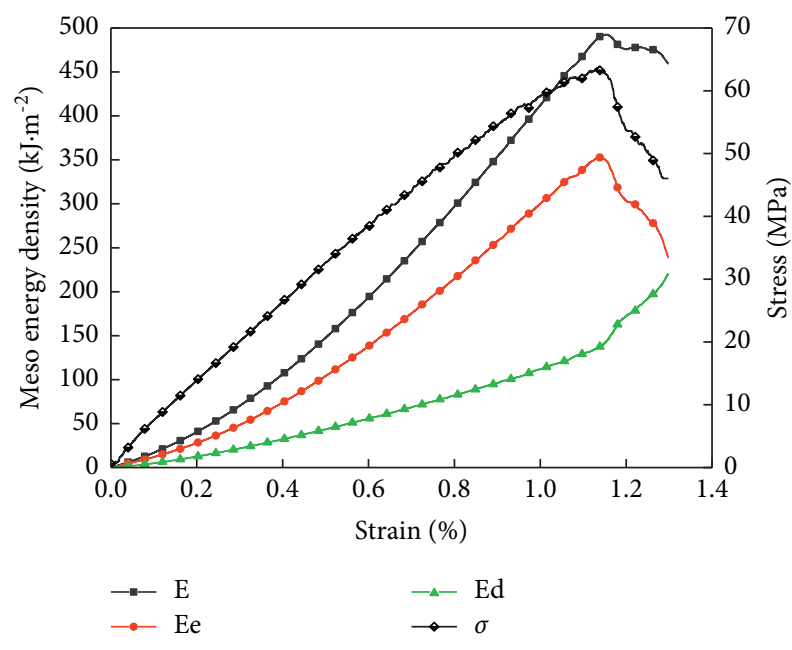

(c)
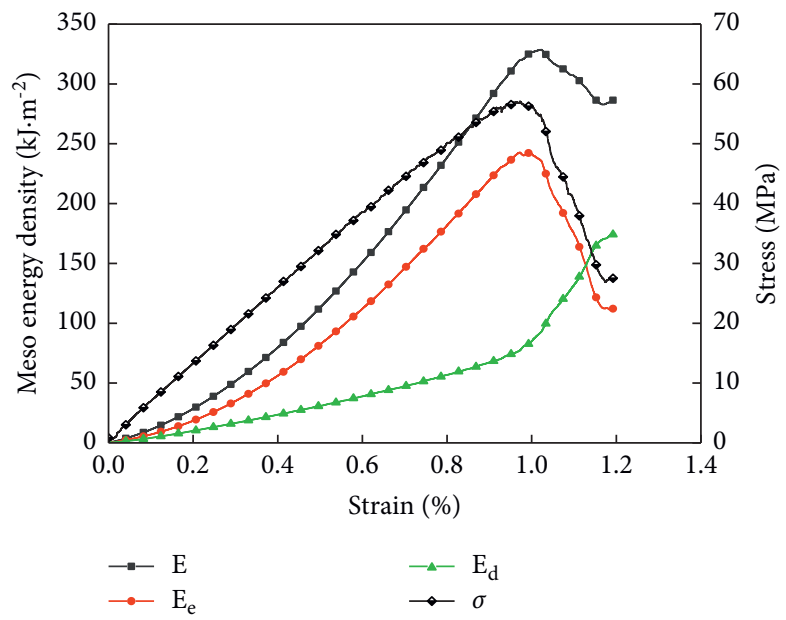

(b)

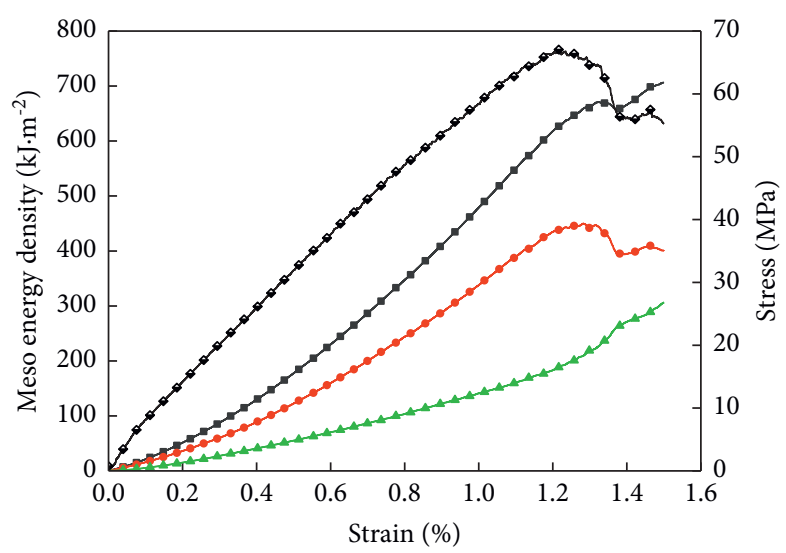

$\rightarrow \mathrm{E}$
$\rightarrow \mathrm{Ee}$

$-\Delta-\mathrm{Ed}$

(d)

FIGURe 22: Meso-energy evolution curves for jointed sandstone under different $\sigma 3$ : (a) $\sigma 3=0 \mathrm{MPa}$, (b) $\sigma 3=5 \mathrm{MPa}$, (c) $\sigma 3=10 \mathrm{MPa}$, and (d) $\sigma 3=15 \mathrm{MPa}$. 


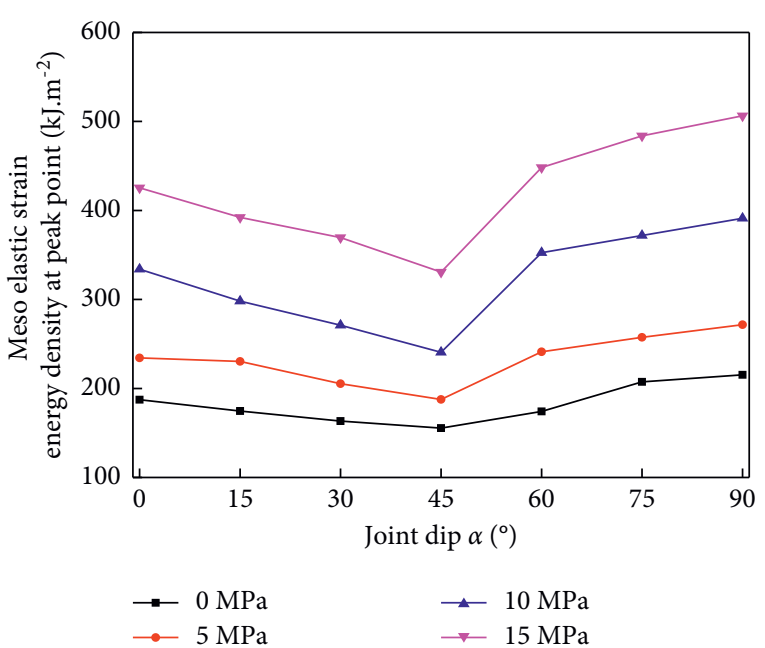

(a)

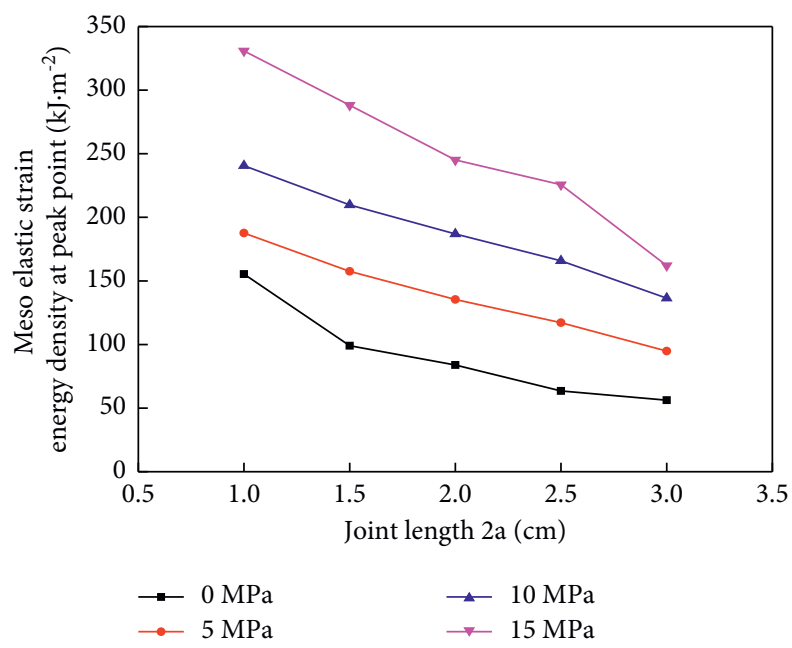

(b)

FIgURE 23: Evolution of the peak strength of jointed sandstone under different $\sigma_{3}$.

energy with $\sigma_{3}$ after the peak of the jointed sandstone at each dip angle is fitted using the equation $y=a+b \sigma_{3}$; the fitting results are shown in Figure 27.

As shown in Figure 27, the fitting correlation is between 0.94 and 0.99 . In the fitting equation, $a$ represents the sudden decrease in the elastic meso-strain energy or the sudden increase in the dissipated meso-energy of the jointed sandstone under uniaxial compression, and $b$ represents the rate of the sudden decrease in the elastic meso-strain energy or the sudden increase in the dissipated meso-energy after the peak of the jointed sandstone under $\sigma_{3}$. The smaller the value of $b$, the greater the rate of the sudden change in the meso-energy will be. As $\alpha$ increases, $b$ initially decreases and then increases. That is, the rate of the abrupt change in the meso-energy after the peak first increases and then decreases for jointed sandstone; the rate of the abrupt change in the meso-energy after the peak is greater for the sandstone with a gentle dip than that with a steep dip. To investigate the mesoscopic damage of sandstones with different $\alpha$ under varying $\sigma_{3}$, the mesoscopic damage level is used to analyse the cumulative meso-damage before the peak and the mutation meso-damage after the peak, as shown in Figure 28.

As shown in Figure 28, as $\alpha$ increases, the cumulative mesoscopic damage level of jointed sandstone before the peak initially increases and then decreases, and the postpeak mutation meso-damage level initially decreases and then increases. The greater the $\sigma_{3}$, the greater the cumulative damage before the peak is, and the smaller the damage after the peak will be. As shown in Figure 29 with the increase in $\sigma_{3}$, the distribution density of microcracks inside sandstones with different $\alpha$ increases; that is, the cumulative damage becomes more severe. When $\sigma_{3}$ is constant, the accumulated meso-damage of the jointed sandstone with a moderate dip is the largest before the peak, and the mutation mesodamage is the smallest after the peak. The jointed sandstone with a steep dip exhibits the opposite trend, and the characteristics of the sandstone with a gentle dip are in between.
In addition, it can also be seen that under the action of $\sigma_{3}$, the failure mode of the jointed sandstone is not controlled by $\alpha$ but is mainly controlled by $\sigma_{3}$. Generally, X-type shear failures or tensile-shear mixed failures are dominant.

Similar to the postpeak meso-energy evolution characteristics of jointed sandstones with different joint dip angles, based on the results of the numerical simulations, the mesoenergy evolution characteristics at the peak points of sandstones with different joint lengths under varying confining pressures are shown in Figure 30.

As shown in Figure 30, with an increase in $\sigma_{3}$, the mesoenergy at the peak point of the sandstones with different joint lengths increases, the proportion of elastic energy decreases, and the proportion of dissipated energy increases. The relationship between $\sigma_{3}$ at the peak point and the elastic meso-strain energy of sandstones with different joint lengths is fitted using the equation $y=a+b \sigma_{3}$, where $a, b$, and $\sigma_{3}$ at the peak point have the same meaning as the parameters in the fitting relationship for the elastic meso-strain energy of sandstones with different joint dip angles. The fitting results are shown in Figure 31. As $2 a$ increases, $b$ initially increases and then decreases, but the increase is not large. When $2 a$ increases from $2.5 \mathrm{~cm}$ to $3.0 \mathrm{~cm}, b$ decreases significantly; that is, when $\sigma_{3}$ is constant, the elastic meso-strain energy accumulation rate of jointed sandstone is not affected within a certain range of $2 a$. When $2 a$ exceeds a certain value, the elastic meso-strain energy accumulation rate decreases as $2 a$ increases. The larger the $\sigma_{3}$ is, the more obvious the anisotropy of effect of the joint length on the elastic strain energy at the peak point will be for jointed sandstone.

Figure 32 shows the sudden change in the meso-energy of sandstones with different joint lengths under varying $\sigma_{3}$ from the peak point to the failure point.

It can be seen from Figure 32 that $\sigma_{3}$ increases the residual meso-energy at the failure point for sandstones with different joint lengths and suppresses the sudden change in the meso-energy after the peak. The relationship between the postpeak meso-energy mutation amplitude with $\sigma_{3}$ is fitted 


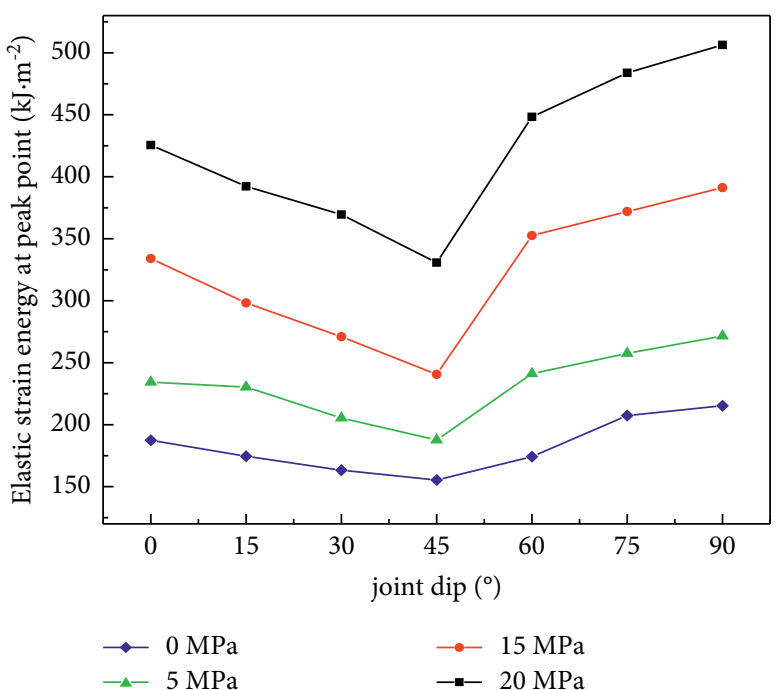

(a)

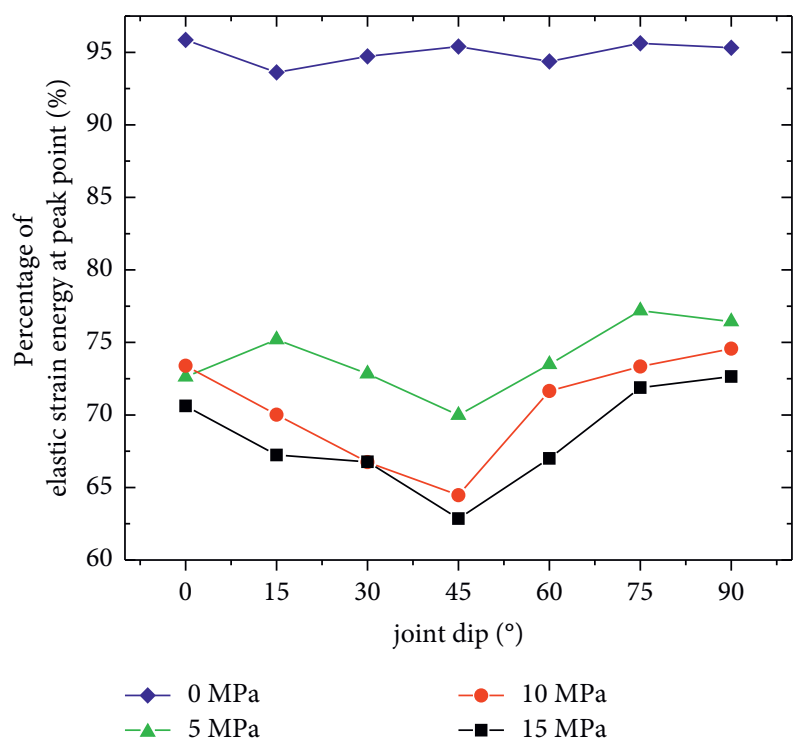

(c)

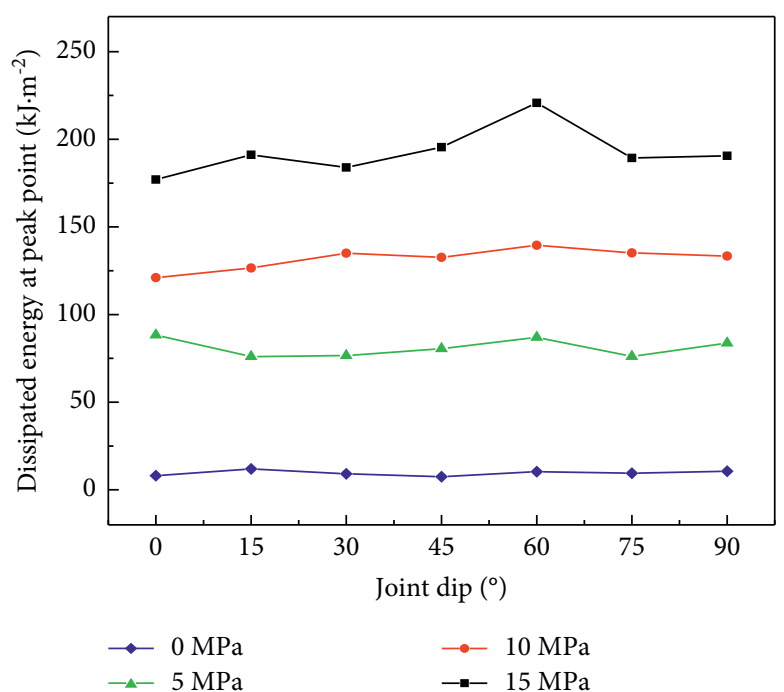

(b)

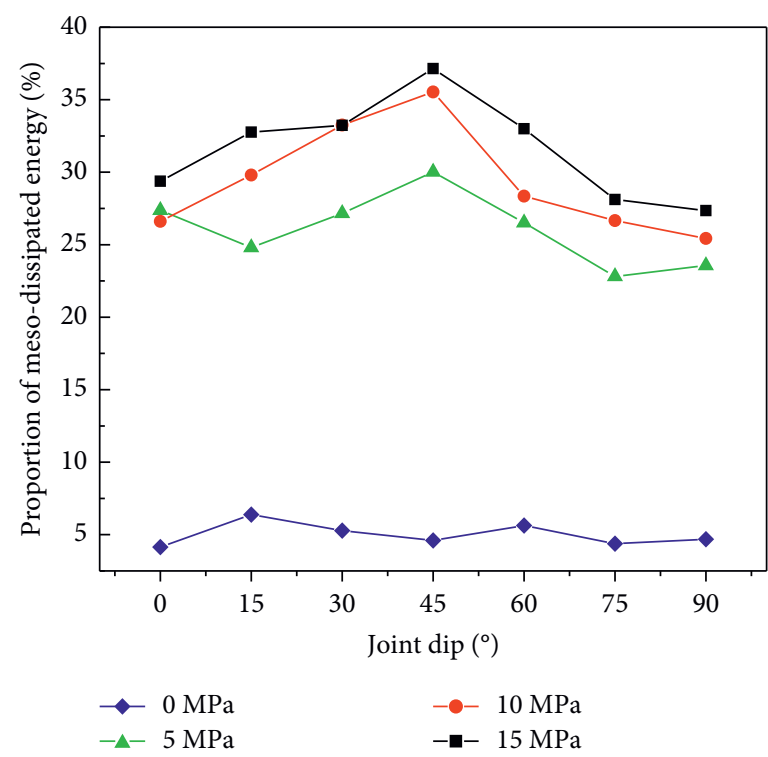

(d)

Figure 24: Mesoscopic energy at the peak point for sandstones with different $\alpha$ under varying $\sigma_{3}$ : (a) elastic strain energy, (b) dissipated energy, (c) percentage of elastic strain energy, and (d) percentage of dissipated energy.

for sandstones with different values of $2 a$, and the fitting results are shown in Figure 33.

As shown in Figure 33, the amplitude of the abrupt change in the meso-energy has a linearly decreasing relationship with $\sigma_{3}$ for sandstones with different $2 a$, and the fitting correlations are between 0.94 and 0.99 . In the fitting equation, $a$ and $b$ have the same meaning as the parameters in the fitting relationship for the energy mutation amplitude after the peak in sandstones with different joint dip angles. With an increase in $2 a, b$ gradually increases, and the rate of decrease of the meso-energy mutation amplitude after the peak gradually decreases in the jointed sandstones. In other words, when $\sigma_{3}$ is constant, the magnitude of the mesoenergy mutation after the peak in the jointed sandstone is inhibited by $\sigma_{3}$ and decreases with an increase in $2 a$. Here, $a$ can reflect the joint length effect on the meso-energy mutation amplitude after the peak in jointed sandstone under a certain $\sigma_{3}$. With an increase in $2 a, a$ gradually decreases and the meso-energy mutation amplitude after the peak gradually decreases. The larger the $\sigma_{3}$, the less obvious the effect of the joint length on the meso-energy mutation amplitude after the peak will be. The mesoscopic damage of sandstones with different $2 a$ under varying $\sigma_{3}$ is shown in Figure 34 .

As shown in Figure 34, with an increase in $2 a$, the cumulative mesoscopic damage level of the jointed sandstone before the peak gradually increases, and the mutational meso-damage after the peak gradually decreases. Moreover, a larger $\sigma_{3}$ will increase the degree of accumulated mesodamage before the peak in sandstones with different $2 a$, while inhibiting the degree of mutation meso-damage after 


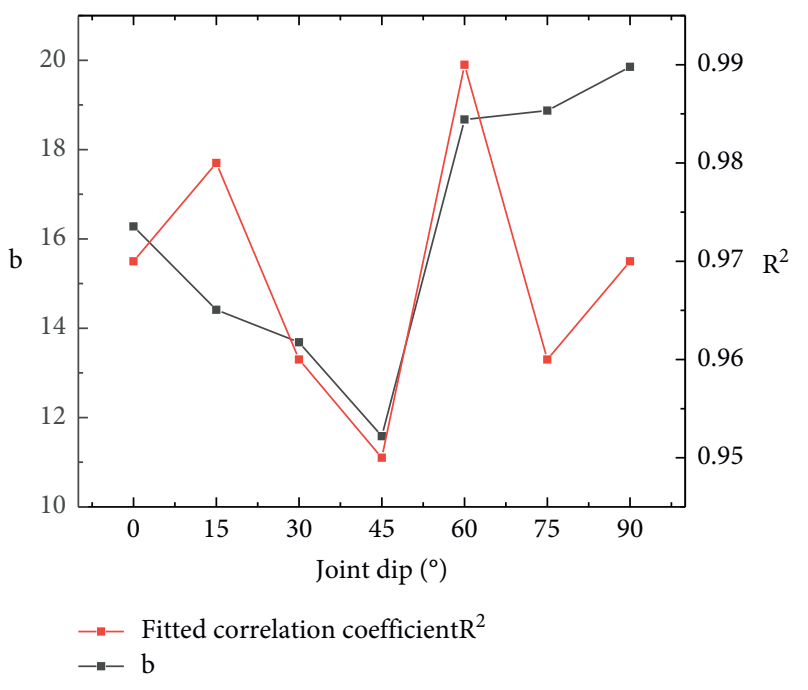

FIGURE 25: Fitting results for the relationship between $\alpha$ and $\sigma_{3}$ at the peak point.

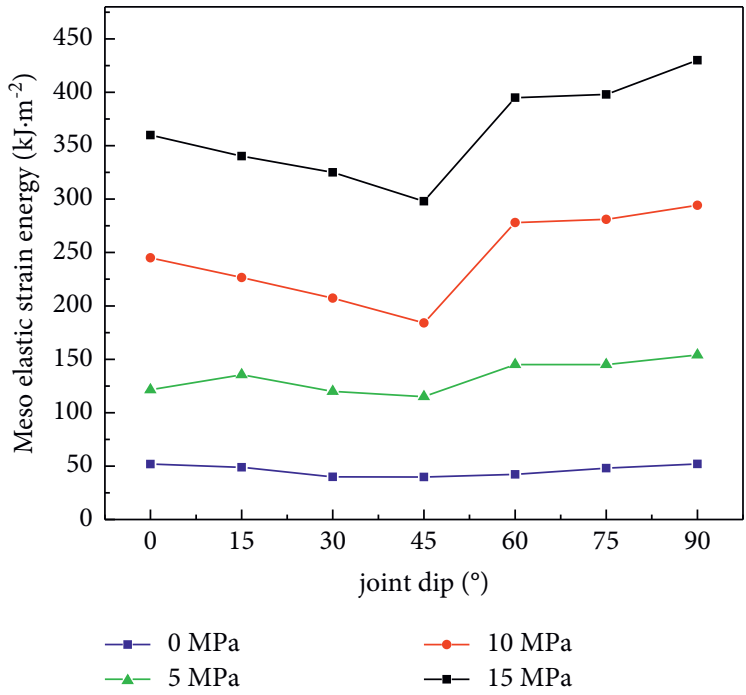

(a)

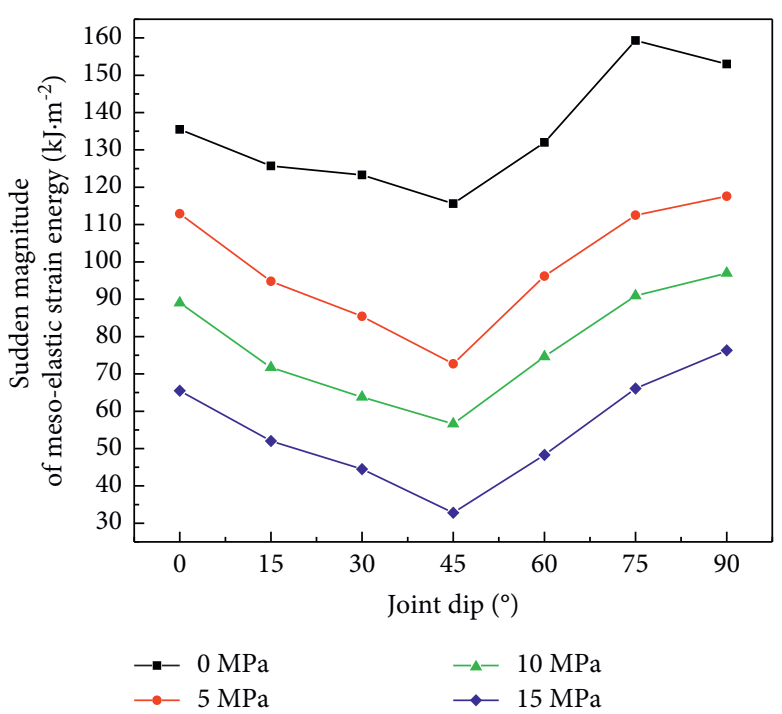

(c)

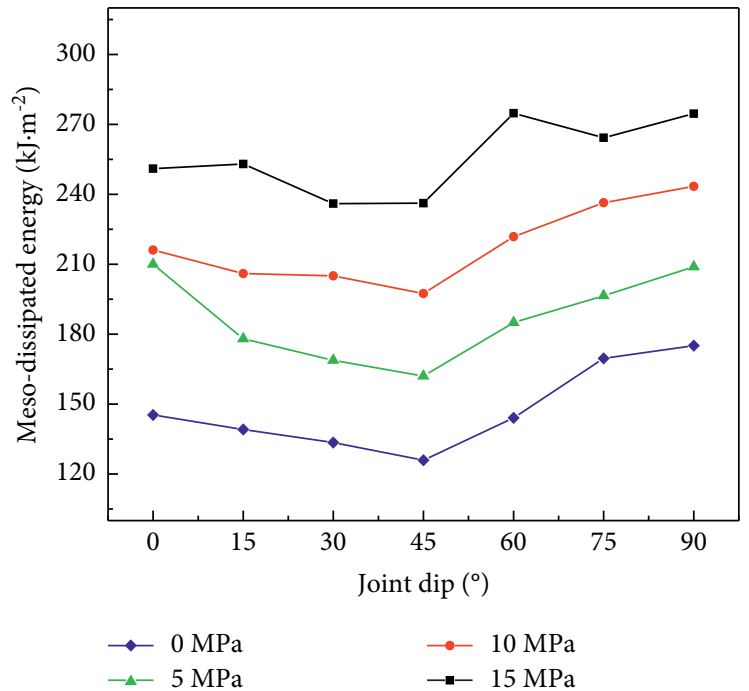

(b)

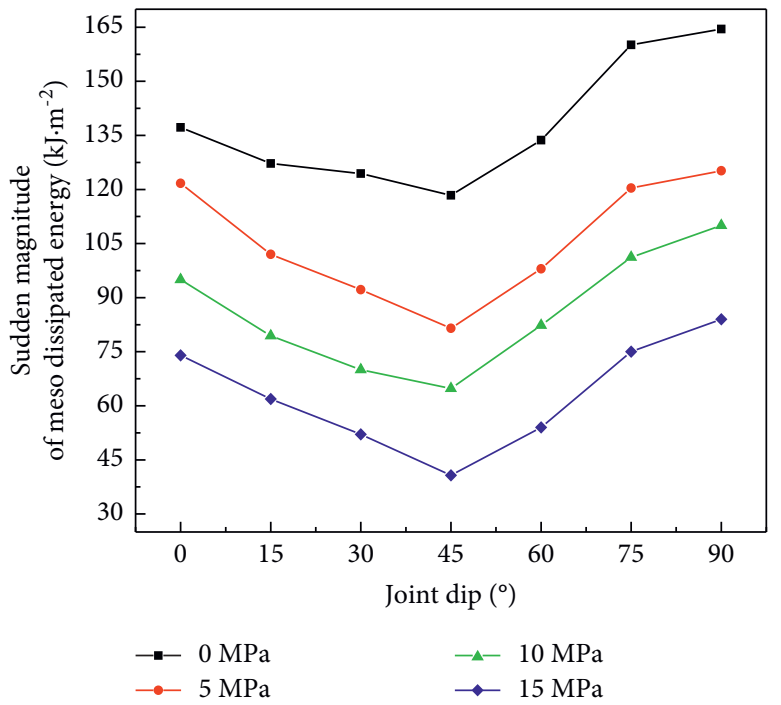

(d)

FiguRe 26: Abrupt change in the meso-energy of sandstones with different $\alpha$ under varying $\sigma 3$ : (a) elastic strain energy, (b) dissipated energy, (c) range of the abrupt change in the elastic strain energy, and (d) range of the abrupt change in the dissipated energy. 


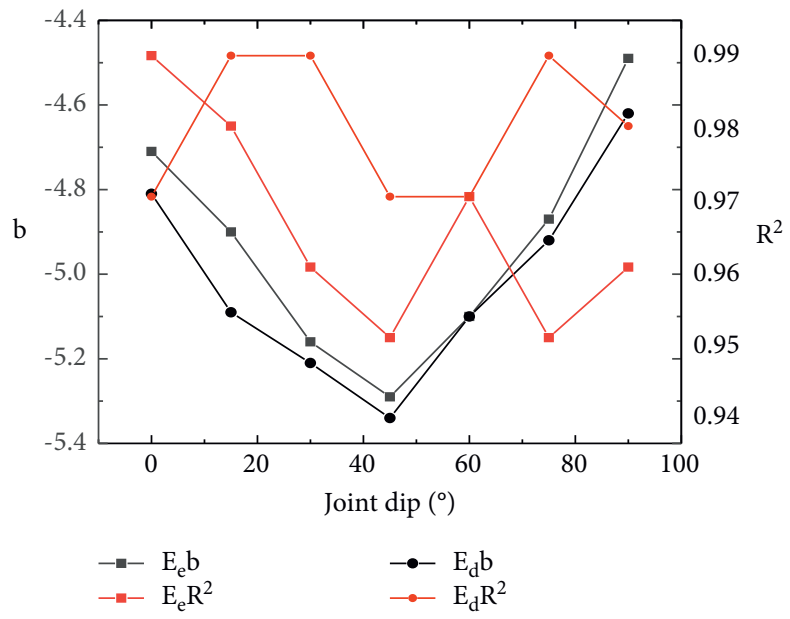

FIGURE 27: Fitting results for the postpeak relationship between $\alpha$ and $\sigma_{3}$.

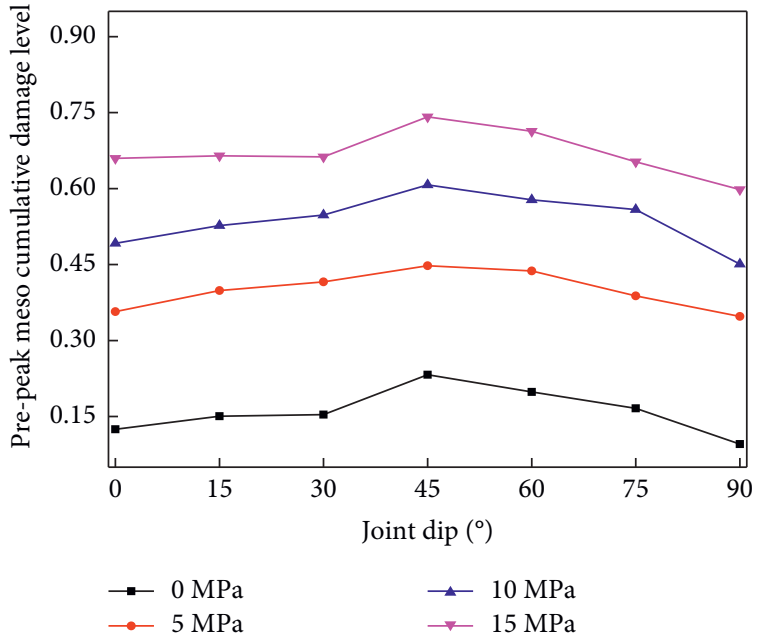

(a)

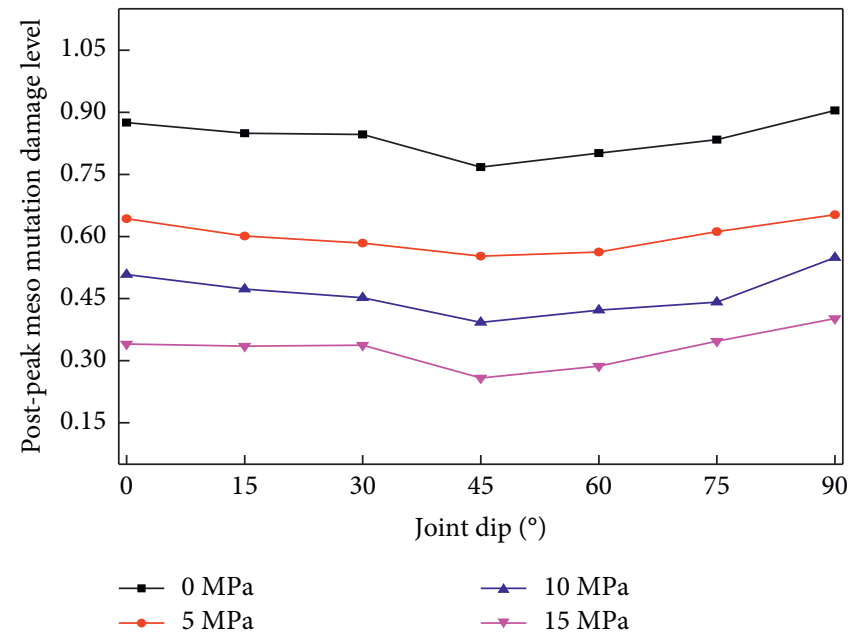

(b)

Figure 28: Meso-damage levels of sandstones with different $\alpha$ under varying $\sigma_{3}$ : (a) prepeak meso-accumulation and (b) postpeak meso-mutation.

the peak. Figure 35 shows that with an increase in $\sigma_{3}$ in sandstones with different $2 a$, the distribution density of microcracks in the sandstones increases. The greater the value of $2 a$, the greater the prepeak cumulative mesodamage of the sandstone will be, and the smaller the postpeak mutational meso-damage will be. The final degree of cracking in the jointed sandstone is consistent with the regular change in the prepeak cumulative damage level. Under the action of $\sigma_{3}$, the final failure mode of sandstones having different $2 a$ is mainly controlled by $\sigma_{3}$. The larger the $\sigma_{3}$ is, the more obvious the X-type shear failure will be.

\section{Discussion}

Based on laboratory experiments, this study uses a PFC numerical simulation to investigate the meso-energy conversion process and phase evolution characteristics of singlejoint sandstones under uniaxial compression. The effect of the joint dip angle and length on the meso-energy damage evolution of jointed sandstones under uniaxial and biaxial compression is analysed, and the effect of the confining pressure under biaxial compression is examined. The main conclusions are as follows:

(1) The total meso-strain energy input during the deformation and failure process of jointed sandstone is transformed into dissipated meso-energy and elastic meso-strain energy. The evolution of the meso-energy can be divided into five stages. These stages are consistent with the overall law of the macroscale energy evolution, with differences reflected in two aspects.

(2) Under uniaxial compression, as the joint dip increases, the energy at the characteristic points of the meso-energy evolution will asymmetrically first decrease and then increase. The ability to accumulate 


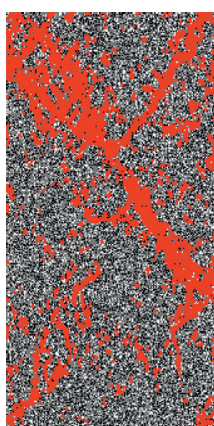

$\sigma_{3}=5 \mathrm{MPa}$

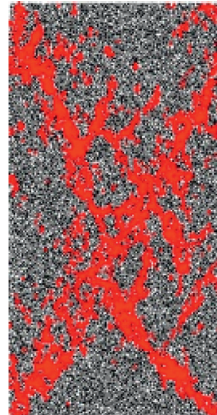

$\sigma_{3}=10 \mathrm{MPa}$

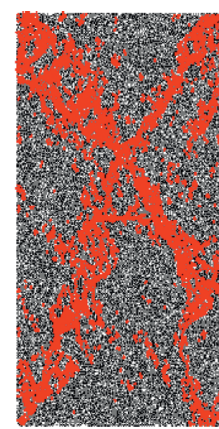

$\sigma_{3}=15 \mathrm{MPa}$

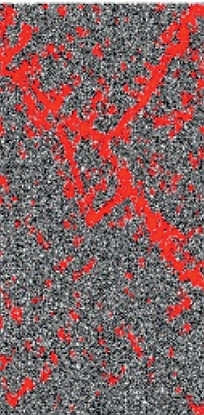

$\sigma_{3}=5 \mathrm{MPa}$

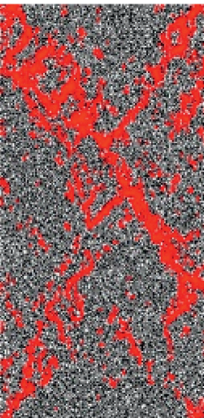

$\sigma_{3}=10 \mathrm{MPa}$

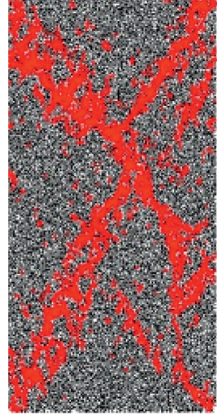

$\sigma_{3}=15 \mathrm{MPa}$

(a)

(b)

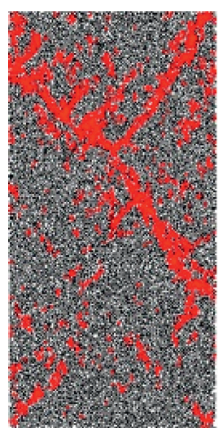

$\sigma_{3}=5 \mathrm{MPa}$

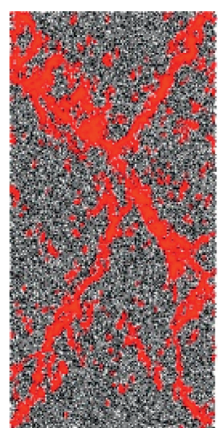

$\sigma_{3}=10 \mathrm{MPa}$

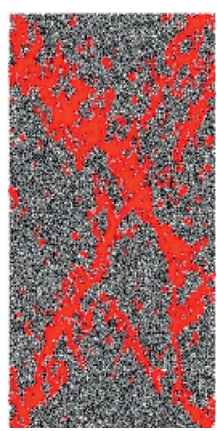

$\sigma_{3}=15 \mathrm{MPa}$

(c)

FIGURE 29: Effect of the confining pressure on the microcrack distribution characteristics of sandstones with different $\alpha$ : (a) $\alpha=0^{\circ}$, (b) $\alpha=45^{\circ}$, and (c) $\alpha=90^{\circ}$.

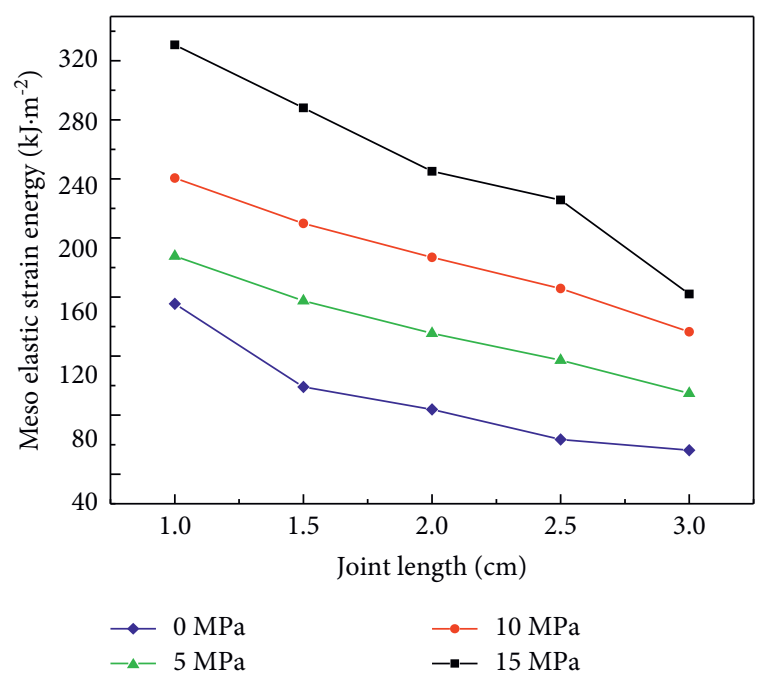

(a)

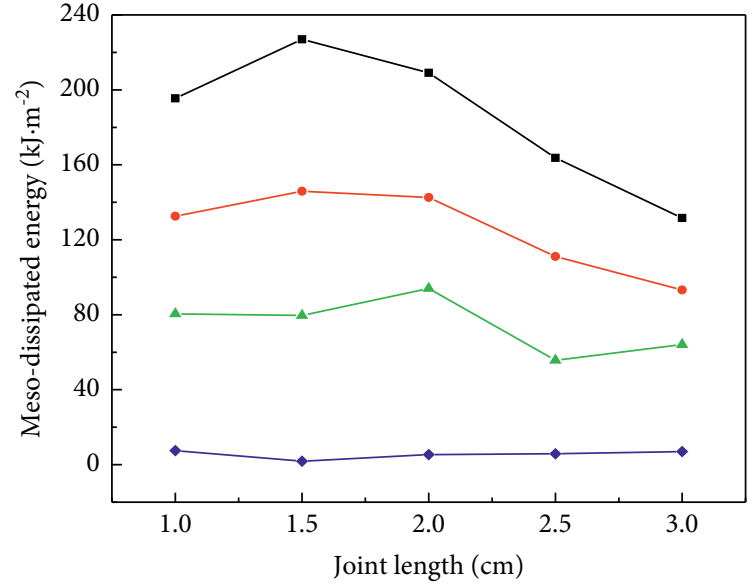

$--10 \mathrm{MPa}$
$--15 \mathrm{MPa}$

(b)

Figure 30: Continued. 


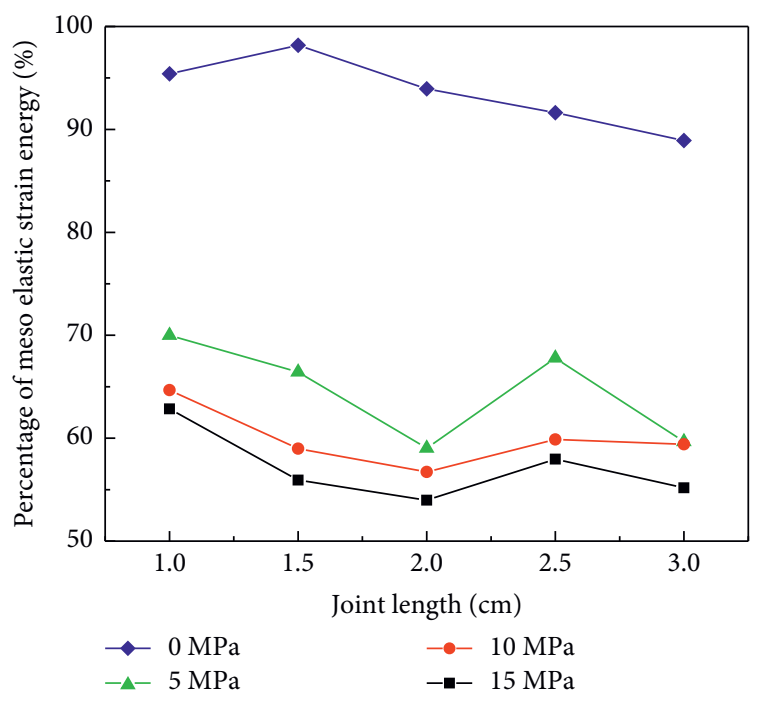

(c)

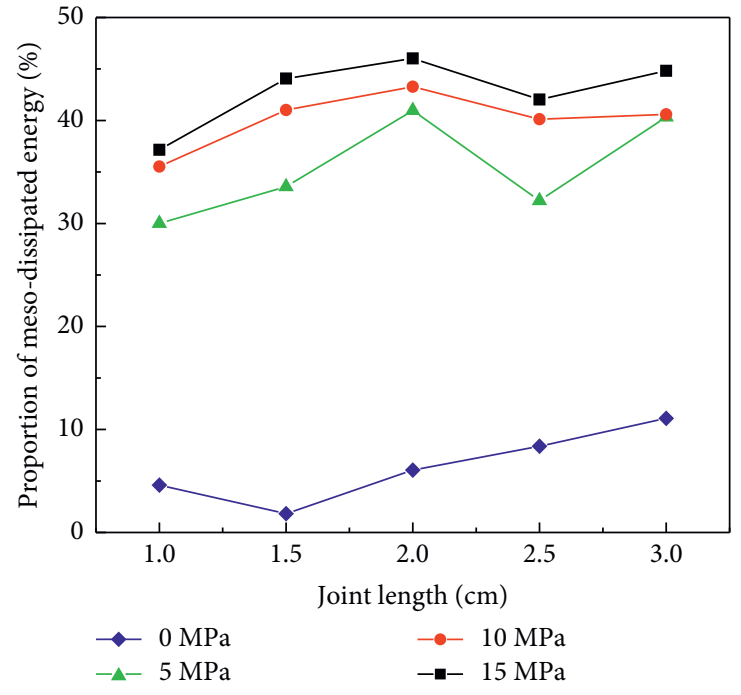

(d)

Figure 30: Mesoscopic energy at the peak point in sandstones with different joint lengths under varying confining pressures: (a) elastic strain energy, (b) dissipated energy, (c) percentage of elastic strain energy, and (d) percentage of dissipated energy.

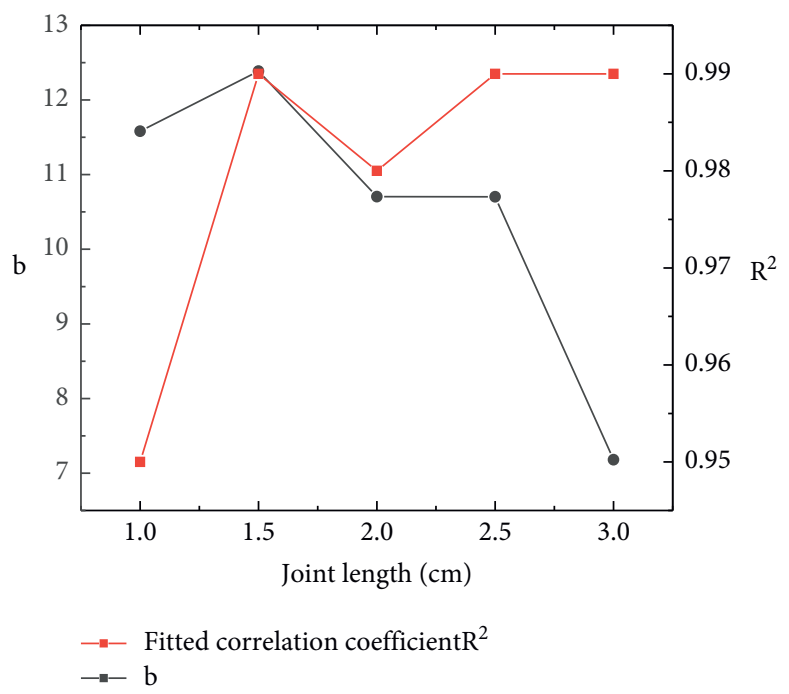

FIGURE 31: Fitting results for the relationship between $2 a$ and $\sigma_{3}$ at the peak point.

energy before the peak is weak in the sandstone with the medium dip angle, the corresponding postpeak mutation damage is slight, and progressive shear failure occurs. The sandstone with a gradual dip angle has a more severe near-X-shaped tensile-shear mixed failure, whereas the sandstone with a steep dip exhibits splitting failure.

(3) Under uniaxial compression, the crack initiation point is significantly affected by the joint length, and the meso-energy degradation at the damage point and peak point decreases with an increase in the joint length. The cumulative damage level before the peak increases with an increase in the joint length. The final failure mode is not affected by the length of the joint and is basically shear failure. The longer the joint, the faster the crack development process before the peak will be after initiation. In addition, the cumulative damage before the peak will be more severe, and the failure process after the peak will be slower.

(4) After comparing the experimental and PFC numerical simulation results for sandstones with different joint dip angles and joint lengths, the reasons for the errors are analysed. The $\mathrm{PFC}^{2 \mathrm{D}}$ numerical simulation method is directly related to its calculation assumptions. There are many irregular weak structural surfaces and tiny cracks in real specimens, and the numerical simulation method cannot accurately simulate these internal conditions. Therefore, there is a large relative error. 


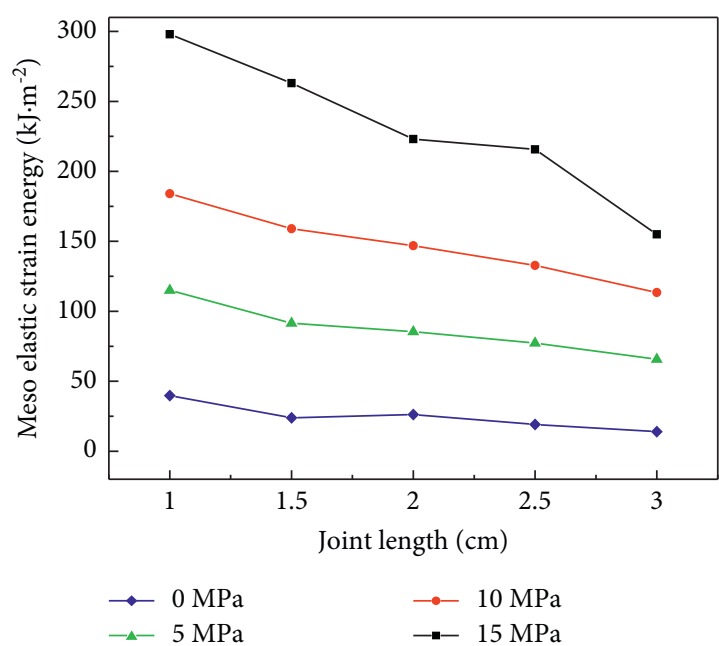

(a)
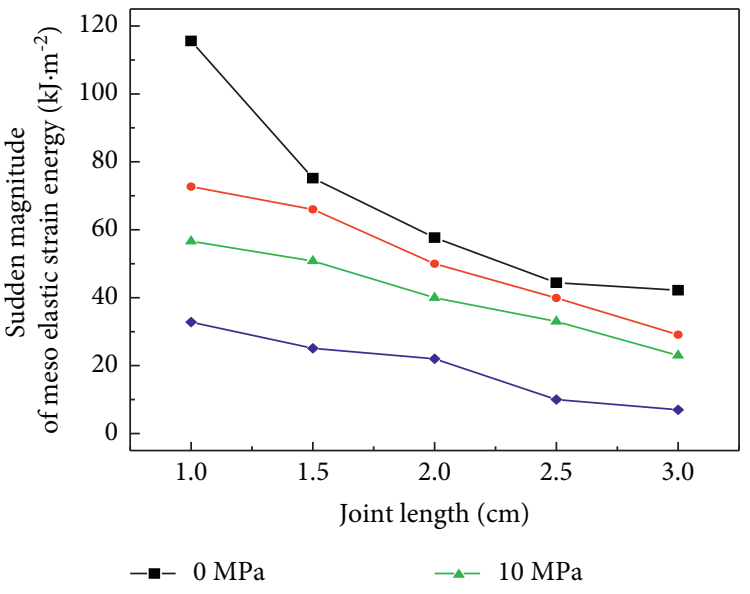

$\rightarrow 5 \mathrm{MPa}$

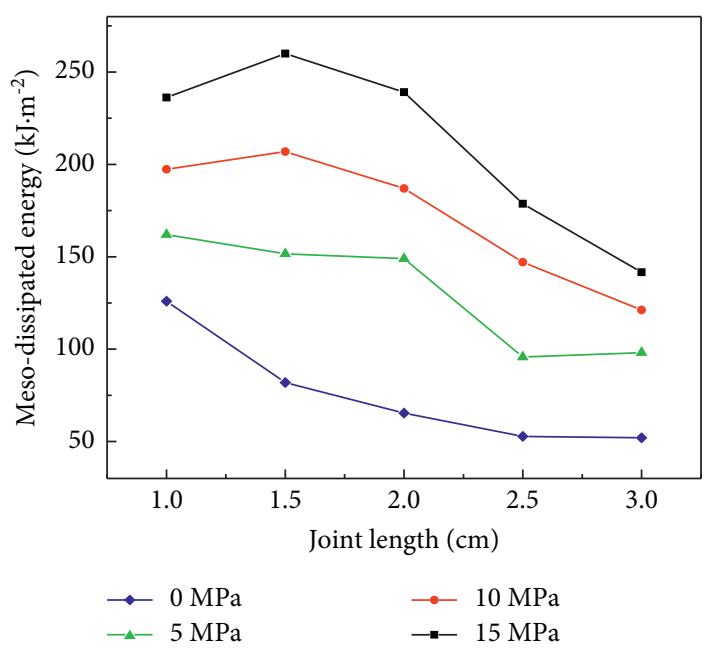

(b)
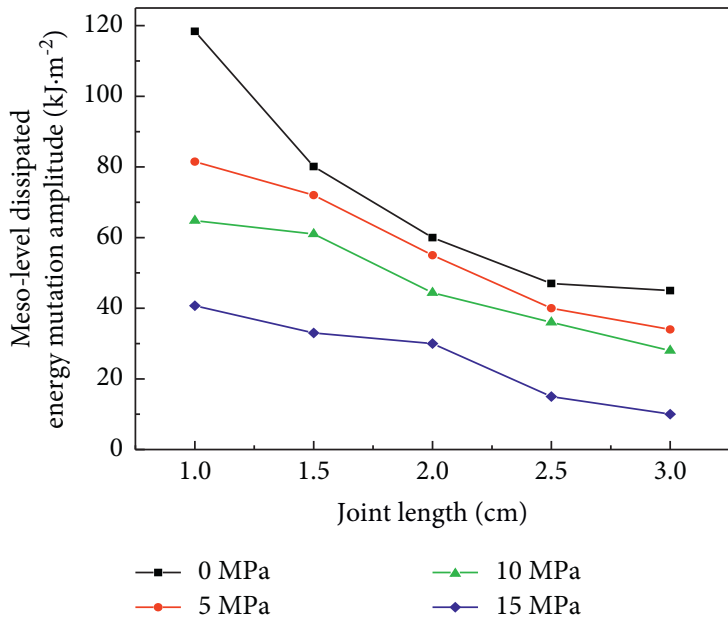

(d)

Figure 32: Abrupt change in the meso-energy of sandstones with different $2 a$ under varying $\sigma_{3}$ : (a) elastic strain energy, (b) dissipation energy, (c) elastic strain energy mutation amplitude, and (d) dissipation energy mutation amplitude.

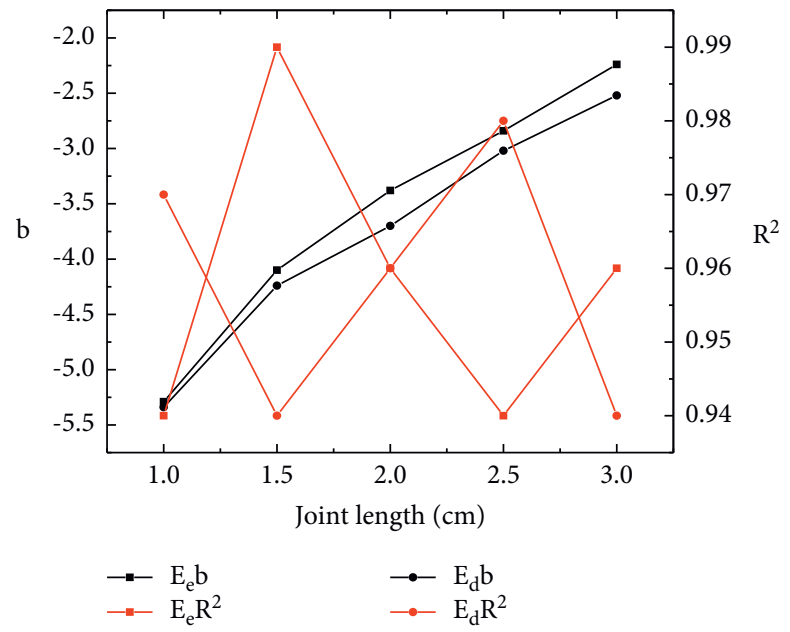

FIgURE 33: Fitting results for the relationship between sandstones with different $2 a$ and $\sigma 3$ after the peak. 


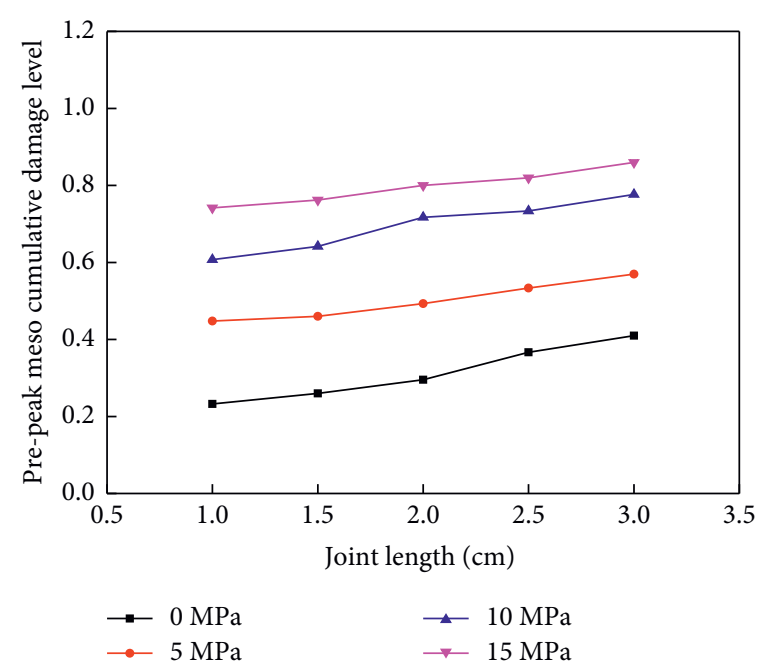

(a)

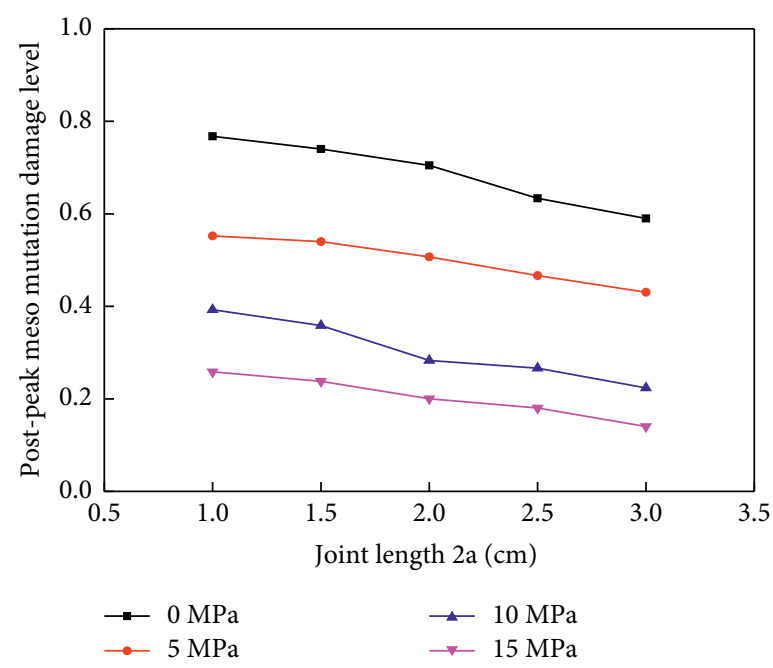

(b)

Figure 34: Mesoscopic damage level of sandstones with different joint lengths under varying confining pressures: (a) prepeak mesoaccumulation and (b) postpeak meso-mutation.

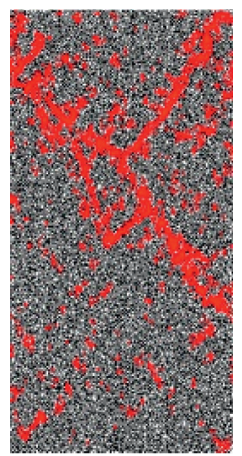

$\sigma_{3}=5 \mathrm{MPa}$

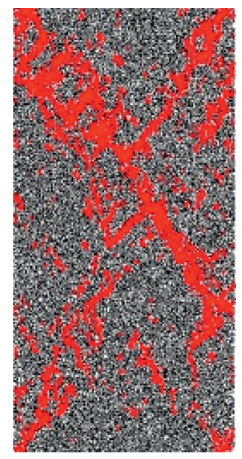

$\sigma_{3}=10 \mathrm{MPa}$

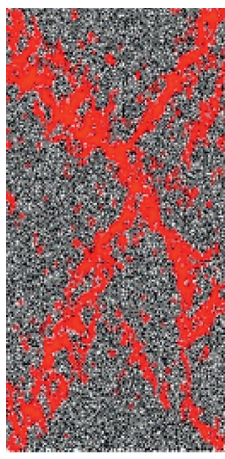

$\sigma_{3}=15 \mathrm{MPa}$

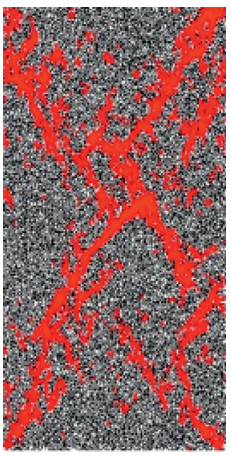

$\sigma_{3}=5 \mathrm{MPa}$

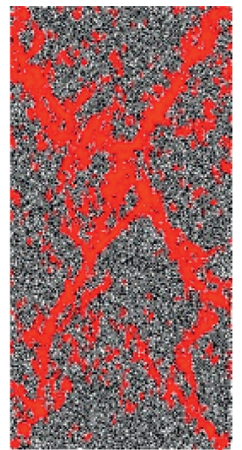

$\sigma_{3}=10 \mathrm{MPa}$

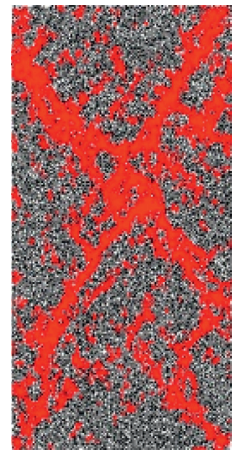

$\sigma_{3}=15 \mathrm{MPa}$

(a)

(b)

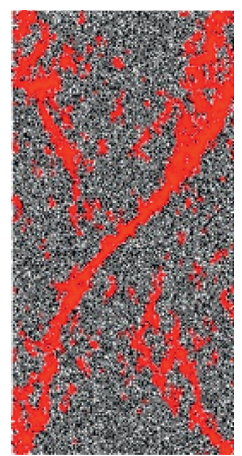

$\sigma_{3}=5 \mathrm{MPa}$

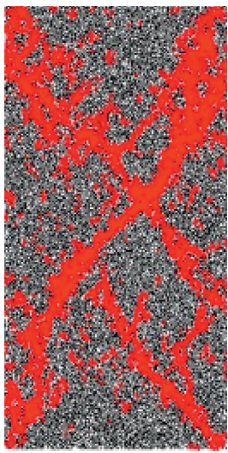

$\sigma_{3}=10 \mathrm{MPa}$

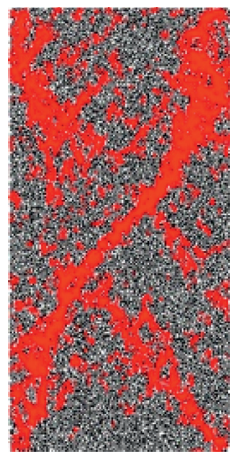

$\sigma_{3}=15 \mathrm{MPa}$

(c)

FigURE 35: Effect of the confining pressure on the microcrack distribution characteristics of sandstones with different $2 a$ : (a) $2 a=1 \mathrm{~cm}$, (b) $2 a=2 \mathrm{~cm}$, and (c) $2 a=3 \mathrm{~cm}$.

(5) Under a certain confining pressure, the elastic mesostrain accumulation rate at the peak point is the fastest for the jointed sandstone with steep dip, followed by the sandstone with a gentle dip; the sandstone with a medium dip has the slowest rate. The reduction rate of the sudden change in the mesoenergy amplitude after the peak follows the same pattern. The postpeak abrupt meso-damage level 
determines the final cracking situation of sandstones with different dip angles.

(6) Under a certain confining pressure, the rate of decrease of the sudden change in the meso-energy amplitude after the peak decreases with an increase in the joint length. The accumulation rate of the elastic meso-strain energy at the peak point is not affected within a certain joint length. When the joint length exceeds a certain value, the accumulation rate of the elastic meso-strain energy decreases. The cumulative damage level before the peak determines the final cracking of the sandstone with different joint lengths. High confining pressure conditions promote the accumulation of damage in the prepeak region and inhibit the meso-energy and damage mutation degree after the peak. The failure mode is mainly controlled by the confining pressure. The higher the confining pressure, the more obvious the effects of the joint length and dip angle on the elastic strain energy at the peak point will be.

\section{Data Availability}

Some or all data, models, or code that support the findings of this study are available from the corresponding author upon reasonable request.

\section{Conflicts of Interest}

The authors declare that they have no known competing financial interests or personal relationships that could have appeared to influence the work reported in this paper.

\section{Acknowledgments}

This work was supported by the National Natural Science Foundation of China (grant no. 51978106).

\section{References}

[1] A.-Z. Hua and M.-Q. You, "Rock failure due to energy release during unloading and application to underground rock burst control," Tunnelling and Underground Space Technology, vol. 16, no. 3, pp. 241-246, 2001.

[2] A. B. Hawkins and B. J. McConnell, "Sensitivity of sandstone strength and deformability to changes in moisture content," The Quarterly Journal of Engineering Geology and Hydrogeology, vol. 25, no. 2, pp. 115-130, 1992.

[3] D. Huang and Y. Li, "Conversion of strain energy in triaxial unloading tests on marble," International Journal of Rock Mechanics and Mining Sciences, vol. 66, pp. 160-168, 2014.

[4] Li Wang, Z. Lu, and Q. Gao, "A numerical study of rock burst development and strain energy release," International Journal of Mining Science and Technology, vol. 22, no. 5, pp. 679-684, 2012.

[5] G.-y. Zhao, B. Dai, L.-j. Dong, and C. Yang, "Energy conversion of rocks in process of unloading confining pressure under different unloading paths," Transactions of Nonferrous Metals Society of China, vol. 25, no. 5, pp. 1626-1632, 2015.

[6] D. Li, Z. Sun, T. Xie, X. Li, and P. G. Ranjith, "Energy evolution characteristics of hard rock during triaxial failure with different loading and unloading paths," Engineering Geology, vol. 228, pp. 270-281, 2017.

[7] Z. Chen, C. He, D. Wu, G. Xu, and W. Yang, "Fracture evolution and energy mechanism of deep-buried carbonaceous slate," Acta Geotechnica, vol. 12, no. 6, pp. 1243-1260, 2017.

[8] Z. Chen, C. He, G. Ma, G. Xu, and C. Ma, "Energy damage evolution mechanism of rock and its application to brittleness evaluation," Rock Mechanics and Rock Engineering, vol. 52, no. 4, pp. 1265-1274, 2019.

[9] G. Wang, L. Zhang, and M. Xu, "Research on damage and failure energy evolution mechanism of non-continuous jointed rock mass under uniaxial compression," Chinese Journal of Geotechnical Engineering, vol. 41, no. 4, pp. 639-647, 2019.

[10] Z. Zhang and F. Gao, "Experimental investigation on the energy evolution of dry and water-saturated red sandstones," International Journal of Mining Science and Technology, vol. 25, no. 3, pp. 383-388, 2015.

[11] R. Peng, Y. Ju, J. G. Wang, H. Xie, F. Gao, and L. Mao, “Energy dissipation and release during coal failure under conventional triaxial compression," Rock Mechanics and Rock Engineering, vol. 48, no. 2, pp. 509-526, 2014.

[12] T. Li, X. Pei, D. Wang, R. Huang, and H. Tang, "Nonlinear behavior and damage model for fractured rock under cyclic loading based on energy dissipation principle," Engineering Fracture Mechanics, vol. 206, pp. 330-341, 2019.

[13] F. Peng, Y. Xu, and F. Dai, "Effects of dynamic strain rate on the energy dissipation and fragment characteristics of cross-fissured rocks," International Journal of Rock Mechanics and Mining Sciences, vol. 138, no. 2021, Article ID 104600, 2021.

[14] F. Peng, F. Dai, Yi Liu, NuW. Xu, and P. Fan, "Effects of coupled static and dynamic strain rates on mechanical behaviors of rock-like specimens containing pre-existing fissures under uniaxial compression," Canadian Geotechnical Journal, vol. 55, pp. 640-652, 2018.

[15] F. Peng, F. Dai, Y. Liu, N. W. Xu, and H. Du, "Coupled effects of static-dynamic strain rates on the mechanical and fracturing behaviors of rock-like specimens containing two unparallel fissure," Engineering Fracture Mechanics, vol. 207, pp. 237-253, 2019.

[16] Y. Liu, F. Dai, L. Dong, N. Xu, and P. Feng, "Experimental investigation on the fatigue mechanical properties of intermittently jointed rock models under cyclic uniaxial compression with different loading parameters," Rock Mechanics and Rock Engineering, vol. 51, no. 1, pp. 47-68, 2018.

[17] D. Huang and D. Cen, "Mechanical response of a single fractured rock sample under uniaxial static-dynamic sequential compression and particle flow simulation of energy dissipation mechanism," Chinese Journal of Rock Mechanics and Engineering, vol. 32, no. 9, pp. 1926-1936, 2013.

[18] G. Zhang, H. Li, X. Xia, J.-r. Li, C. Yu, and J.-s. Liu, "Study on the evolution of energy and damage of rock under uniaxial compression," Rock and Soil Mechanics, vol. 36, no. S1, pp. 94-100, 2015.

[19] S. Xie, H. Lin, Y. Wang et al., "Nonlinear shear constitutive model for peak shear-type joints based on improved Harris damage function," Archives of Civil and Mechanical Engineering, vol. 20, no. 3, p. 95, 2020.

[20] L. N. Y. Wong and H. H. Einstein, "Crack coalescence in molded gypsum and carrara marble: Part 2-microscopic observations and interpretation," Rock Mechanics and Rock Engineering, vol. 42, no. 3, pp. 513-545, 2009. 
[21] H. Yang, H. Lin, Y. Wang, R. Cao, J. Li, and Y. Zhao, "Investigation of the correlation between crack propagation process and the peak strength for the specimen containing a single pre-existing flaw made of rock-like material," Archives of Civil and Mechanical Engineering, vol. 21, no. 2, p. 68, 2021.

[22] S. Chehreghani, M. Noaparast, B. Rezai, and S. Ziaedin Shafaei, "Bonded-particle model calibration using response surface methodology," Particuology, vol. 32, pp. 141-152, 2016.

[23] Xu-Xu Yang and P. H. S. W. Kulatilake, "Effect of joint micro mechanical parameters on a jointed rock block behavior adjacent to an underground excavation: a particle flow approach," Geotechnical \& Geological Engineering, vol. 3, pp. 1-23, 2019.

[24] W. Li, X. Zhou, J. W. Carey, L. P. Frash, and G. Cusatis, "Multiphysics lattice discrete particle modeling (M-LDPM) for the simulation of shale fracture permeability," Rock Mechanics and Rock Engineering, vol. 51, no. 12, pp. 3963-3981, 2018.

[25] X. Xu, S. Wu, Y. Gao, and M. Xu, "Effects of micro-structure and micro-parameters on Brazilian tensile strength using flatjoint model," Rock Mechanics and Rock Engineering, vol. 49, no. 9, pp. 3575-3595, 2016.

[26] F. Dai, Y. Xu, T. Zhao, N.-w. Xu, and Y. Liu, "Loading-ratedependent progressive fracturing of cracked chevron-notched Brazilian disc specimens in split Hopkinson pressure bar tests," International Journal of Rock Mechanics and Mining Sciences, vol. 88, pp. 49-60, 2016.

[27] J. Liu and J. Wang, "Stress evolution of rock-like specimens containing a single fracture under uniaxial loading: a numerical study based on particle flow code," Geotechnical \& Geological Engineering, vol. 36, no. 3, pp. 1-14, 2017.

[28] A. Al-R. Rashid and V. George, "On the coupling of anisotropic damage and plasticity models for ductile materials," International Journal of Solids and Structures, vol. 40, no. 11, pp. 2611-2643, 2003.

[29] X. P. Zhou, "Triaxial compressive behavior of rock with mesoscopic heterogenous behavior: strain energy density factor approach," Theoretical and Applied Fracture Mechanics, vol. 45, no. 1, pp. 46-63, 2006.

[30] D. O. Potyondy and P. A. Cundall, "A bonded-particle model for rock," International Journal of Rock Mechanics and Mining Sciences, vol. 41, no. 8, pp. 1329-1364, 2004.

[31] X. P. Zhang and L. N. Y. Wong, "Cracking processes in rocklike material containing a single flaw under uniaxial compression: a numerical study based on parallel bonded-particle model approach," Rock Mechanics and Rock Engineering, vol. 45, no. 5, pp. 711-737, 2012.

[32] A. C P., Verification Problems and Example Applications, Itasca Consluting Group, Minneeapolis, 2000.

[33] Z. Zheng, "Energy transfer process in rock deformation and analysis of rock deformation dynamics," Science in China (Section B Chemistry, Life Sciences, Geosciences), vol. 5, pp. 524-537, 1990.

[34] M. You, "The relationship between young's modulus and confining pressure of rock specimens," Chinese Journal of Rock Mechanics and Engineering, vol. 1, pp. 53-60, 2003.

[35] Z. Chen, C. He, D. Wu, and L.-W. Gan, "Mechanical properties and energy damage evolution mechanism of deepburied carbonaceous phyllite," Rock and Soil Mechanics, vol. 39, no. 2, pp. 445-456, 2018.

[36] T. Wen, H. Tang, Y. Liu, and K. Wang, "Energy and damage analysis of triaxial compression of slate under different confining pressures," Coal Geology and Prospecting, vol. 44, no. 3, pp. 80-86, 2016.

[37] H. Song, J. Zuo, C. Yan, and L. Li, "Improved energy drop coefficient based on the energy characteristics of the whole process of rock failure," Rock and Soil Mechanics, vol. 40, no. 01, pp. 91-98, 2019. 